\title{
Characterization of a boreal convective boundary layer and its impact on atmospheric chemistry during HUMPPA-COPEC-2010
}

\author{
H. G. Ouwersloot ${ }^{1,2}$, J. Vilà-Guerau de Arellano ${ }^{1}$, A. C. Nölscher ${ }^{2}$, M. C. Krol ${ }^{1}$, L. N. Ganzeveld ${ }^{3}$, C. Breitenberger ${ }^{2}$, \\ I. Mammarella ${ }^{4}$, J. Williams ${ }^{2}$, and J. Lelieveld ${ }^{2}$ \\ ${ }^{1}$ Meteorology and Air Quality, Wageningen University, Wageningen, The Netherlands \\ ${ }^{2}$ Max Planck Institute for Chemistry, Mainz, Germany \\ ${ }^{3}$ Earth System Sciences - Climate Change, Wageningen University, Wageningen, The Netherlands \\ ${ }^{4}$ Department of Physics, 00014 University of Helsinki, Helsinki, Finland
}

Correspondence to: H. G. Ouwersloot (huug.ouwersloot@wur.nl)

Received: 13 April 2012 - Published in Atmos. Chem. Phys. Discuss.: 1 June 2012

Revised: 5 September 2012 - Accepted: 27 September 2012 - Published: 15 October 2012

\begin{abstract}
We studied the atmospheric boundary layer (ABL) dynamics and the impact on atmospheric chemistry during the HUMPPA-COPEC-2010 campaign. We used vertical profiles of potential temperature and specific moisture, obtained from 132 radio soundings, to determine the main boundary layer characteristics during the campaign. We propose a classification according to several main ABL prototypes. Further, we performed a case study of a single day, focusing on the convective boundary layer, to analyse the influence of the dynamics on the chemical evolution of the ABL. We used a mixed layer model, initialized and constrained by observations. In particular, we investigated the role of large scale atmospheric dynamics (subsidence and advection) on the ABL development and the evolution of chemical species concentrations. We find that, if the large scale forcings are taken into account, the ABL dynamics are represented satisfactorily. Subsequently, we studied the impact of mixing with a residual layer aloft during the morning transition on atmospheric chemistry. The time evolution of $\mathrm{NO}_{\mathrm{x}}$ and $\mathrm{O}_{3}$ concentrations, including morning peaks, can be explained and accurately simulated by incorporating the transition of the ABL dynamics from night to day. We demonstrate the importance of the ABL height evolution for the representation of atmospheric chemistry. Our findings underscore the need to couple the dynamics and chemistry at different spatial scales (from turbulence to mesoscale) in chemistry-transport models and in the interpretation of observational data.
\end{abstract}

\section{Introduction}

The atmospheric boundary layer (ABL) dynamics and their impact on atmospheric chemistry are studied by combining field observations, taken during the HUMPPA-COPEC-2010 campaign (Williams et al., 2011), with a modelling study. HUMPPA-COPEC-2010 took place in the boreal forest. This ecosystem, located roughly between $50^{\circ}$ and $65^{\circ} \mathrm{N}$, covers $8 \%$ of the global land surface and $27 \%$ of the forested area, extending over $15 \times 10^{6} \mathrm{~km}^{2}$ (Williams et al., 2011). Therefore, its impact on the global atmospheric chemistry and physics is significant. Since it contains over $10 \%$ of the total carbon present in the combined ecosystems on Earth, perturbations in the climate of the Northern Hemisphere could lead to changes in the carbon cycle (including emissions of volatile organic compounds, VOCs) and aerosol formation and consequently alter the atmospheric composition (Sellers et al., 1997). Considering the large extent of the boreal forest, perturbations in this ecosystem may alter the dynamics and chemistry at different temporal and spatial scales, possibly up to the entire globe. Therefore, it is relevant and timely to study the atmospheric processes over the boreal forest at a range of scales in order to understand the interactions between the dynamics and chemistry. Here, we largely focus on the processes occurring at smaller spatial scales, which are influenced by the diurnal variability of the ABL.

During the HUMPPA-COPEC-2010 campaign, which took place at the Finnish SMEAR II station from 12 July to 12 August 2010, special emphasis was placed on obtaining a 
complete data set of surface and atmospheric measurements to comprehensively characterize the atmospheric physics and chemistry. Guided and constrained by this data, we focus on the influence of large scale forcings and transitions in the morning from nocturnal to daytime conditions on the boreal atmospheric boundary layer dynamics and the associated atmospheric chemistry. Our research extends the analyses of previous campaigns, like the Boreal Ecosystem-Atmosphere Study (BOREAS) (Sellers et al., 1997). BOREAS was conducted in the Canadian forest, aimed at improving the understanding of interactions between the boreal forest biome and the lower atmosphere (Sellers et al., 1997). Observations included dynamical, ecological and biogeochemical variables. The latter included observations of the trace gases $\mathrm{CO}_{2}, \mathrm{CH}_{4}$ and non-methane hydrocarbons. Even though the boundary layer dynamics were analysed (Barr and Betts, 1997; Davis et al., 1997), their evolution was not represented using models to identify and quantify the driving processes. In addition, their impact on the atmospheric chemistry was not considered.

At the SMEAR II station in Hyytiälä $\left(61^{\circ} 51^{\circ} \mathrm{N}, 24^{\circ} 17^{\circ} \mathrm{E}\right.$, $181 \mathrm{~m}$ a.s.l.) continuous observations are performed (Hari and Kulmala, 2005). The station is designed to study the transport of aerosols (Kulmala et al., 2001), gases, energy and momentum between the soil, the air within the canopy and the ABL. Due to the focus of SMEAR II, all observations are performed in the soil, the canopy and the lower part of the ABL. Previous observational campaigns at this site mostly focused on aerosol studies (Nilsson et al., 2001).

During the HUMPPA-COPEC-2010 campaign the standard instruments of the SMEAR II site were complemented with additional equipment. An overview of the gas and aerosol measurement instruments is given in Table 1 of Williams et al. (2011). To be able to characterize the ABL evolution, additional observations were made to obtain vertical profiles of the meteorological variables, using a Cessna aircraft and radiosondes. The campaign turned out to be of particular interest due to anomalously high temperatures that might be representative of future boreal climates (Williams et al., 2011). Since the atmospheric temperature affects the surface latent and sensible heat fluxes (van Heerwaarden et al., 2010), future climates may be characterized by different ABL dynamics.

Concentrations of chemical species in the atmosphere are governed by surface exchange, chemical processes and dynamics in the ABL. Therefore, it is imperative to correctly represent the ABL dynamics when interpreting or predicting atmospheric chemistry (Davis et al., 1994; Ganzeveld et al., 2008; Vilà-Guerau de Arellano et al., 2011). A primary goal of our research is to determine how the growth of the ABL influences atmospheric chemistry. The ABL height development influences the chemical evolution of the boundary layer in two ways. First, the actual height of the ABL can be considered as a mixing volume in which reactive compounds are released and interact. During the day, the height of this layer increases non-linearly from values as low as $100 \mathrm{~m}$ in the morning to values that can exceed $2 \mathrm{~km}$ in the afternoon. Second, the growth of the boundary layer determines the entrainment of air from the free troposphere into the boundary layer. This entrained air generally has different thermodynamic and chemical properties than air in the ABL.

In this paper we classify different boundary layer prototypes that correspond to the most representative vertical potential temperature profiles. These prototypes correspond to stable, convectively mixed and conditionally unstable boundary layers. This classification of the structure of the ABL enables the identification of important processes for atmospheric chemistry during HUMPPA-COPEC-2010, like the intensity of mixing, turbulent time scales, the atmospheric dilution capacity and the entrainment of free tropospheric air. An overview of these processes is given in Table 1 of Ouwersloot et al. (2011).

We further examine the boundary layer dynamics for a single day with particularly intensive observations, using a mixed layer model (MXL). Emphasis is placed on how atmospheric chemistry is affected by the ABL height evolution. The day is selected because important processes took place that can be easily overlooked when analysing the impact of the boundary layer dynamics on chemistry. These processes, associated with temporal transitions and large-scale forcings, include subsidence, the advection of air masses and, in the morning, the connection with a residual boundary layer from the previous day. We complete the study by evaluating the effectiveness of the applied observational strategy during HUMPPA-COPEC-2010 in characterizing the ABL dynamics.

The next section addresses the methodology of this study. Subsequently, the representation of the boundary layer height during one representative day in the HUMPPA-COPEC-2010 campaign is presented. This is followed by an illustration of its importance for accurately modelling atmospheric chemistry. Finally, the strategy for obtaining meteorological data during field campaigns is discussed.

\section{Methods}

In this study, meteorological and atmospheric chemistry observations are combined with numerical experiments. Some observations serve as initial and boundary conditions, while others are compared to the numerical model results. The upper atmospheric conditions are determined by radiosondes. These observations encompass both the boundary layer and free troposphere. The evolution of the atmospheric conditions near the Earth's surface is monitored at the SMEAR II measuring station. The chemical observational techniques used are described in Table 1 of Williams et al. (2011). We focus on the $\mathrm{O}_{3}$ observations with the ultraviolet absorption/fluorescence (UV) method and the $\mathrm{NO}$ and $\mathrm{NO}_{2}$ observations with the chemiluminescence (CLD) method, which 
were all performed by the Max Planck Institute for Chemistry at a height of $24 \mathrm{~m}$ above the ground, approximately $9 \mathrm{~m}$ above the canopy (Mammarella et al., 2009). Since no observations are made in the mixed layer above the surface layer, this data is used as first estimates for the boundary layer average values.

Two complementary numerical techniques are used: the mixed layer model is applied to characterize the boundary layer dynamics and their role in atmospheric chemistry, while vertical profiles generated in the numerical experiments with a Large-Eddy Simulation (LES) model act as virtual radio soundings for the discussion of the observed radiosonde profiles. More specific information is given in the following sections.

\subsection{Radiosondes}

During the campaign, 175 GRAW DFM-06 radiosondes were launched from a clear area at approximately $300 \mathrm{~m}$ distance from the main observational site. In principle, five radiosondes were launched per day at the local daylight saving times (LT, UTC+3) 03:00, 09:00, 12:00, 15:00 and 21:00. The local daylight saving time is ahead of the local solar time by $1 \mathrm{~h} 29 \mathrm{~min}$. During intensive observation periods (IOP), the frequency of radiosonde launches was increased to intervals of maximum two hours. These events took place from 16 July 21:00 to 17 July 18:00, from 21 July 21:00 to 22 July 18:00, from 28 July $21: 00$ to 29 July 18:00 and from $5 \mathrm{Au}$ gust 18:00 to 6 August 18:00. The observations of 6 August will be analysed in more detail.

Data transmitted by the sonde each second was received by an antenna placed at a nearby building. As well as a GPS device, each sonde included a temperature and a humidity sensor. The GPS coordinates were used to determine the altitude and geographical location of the sonde, as well as the wind velocities. The determined position is accurate within $10 \mathrm{~m}$. The temperature sensor measured with an accuracy of $0.2^{\circ} \mathrm{C}$ and the humidity sensor measured the relative humidity with an accuracy of $2 \%$. The software of the ground station determined the pressure profile by combining these observations with the surface pressure. From the combination of altitude, pressure, temperature and relative humidity data, the profiles of the potential temperature, $\theta$, and specific humidity, $q$, are determined. This study focuses on the lowest $3000 \mathrm{~m}$ of these profiles.

\subsection{SMEAR II data}

Data near the surface was collected at the boreal forest observational station SMEAR II (Hari and Kulmala, 2005). The standard observations include meteorological data, aerosols and the concentrations of several chemical species $\left(\mathrm{CO}_{2}\right.$, $\mathrm{H}_{2} \mathrm{O}, \mathrm{CO}, \mathrm{O}_{3}, \mathrm{SO}_{2}, \mathrm{NO}$ and $\mathrm{NO}_{2}$ ). In addition, the turbulent fluxes of temperature, moisture, momentum, aerosols, $\mathrm{CO}_{2}$, $\mathrm{O}_{3}$ and several volatile organic compounds are measured. For this study, the heat fluxes, surface pressure, relative humidity and temperature observations are used.

The sensible heat flux, $H$, and the latent heat flux, LE, were determined using 30-min averages of $10 \mathrm{~Hz}$ Eddy Covariance measurements at a height of $23 \mathrm{~m}$ (Mammarella et al., 2009). The observations were made above the canopy top, which was located at approximately $15 \mathrm{~m}$ height. As such they can be considered as appropriate surface forcings for the development of the ABL and can be directly related to the ABL dynamics observed from the radiosonde profiles.

The observational data of surface pressure and the relative humidity and temperature at $50 \mathrm{~m}$ height originate from the SMEAR smartSearch database (Junninen et al., 2009). These data are converted to potential temperature and specific humidity in a similar way as the radiosonde data.

\subsection{Mixed layer model (MXL)}

To represent and subsequently interpret the observational data, a mixed layer model is used that is coupled to a chemical module (Tennekes, 1973; Vilà-Guerau de Arellano et al., 2009). This model is based on the zeroth-order mixed layer assumption that during the day turbulent mixing is vigorous enough to result in a well-mixed ABL. Thus, the model is similar to a chemical box model with an evolving upper boundary. Mixed layer theory assumes that conserved scalar variables are uniformly distributed in the vertical direction and that their fluxes are therefore characterized by linear profiles. A thermal inversion layer caps the ABL and separates it from the free troposphere. Both the thermal inversion layer and the surface layer (lowest $10 \%$ of the boundary layer, Stull, 1988) are considered to be thin compared to the total boundary layer. This approach has first been used by Lilly (1968), Tennekes (1973), Carson (1973) and Betts (1973). The vertical profiles of the evaluated quantities show a discontinuity at the height of the inversion, above which they linearly change with height in the free troposphere according to their free tropospheric gradients. This simplified representation of the $\mathrm{ABL}$, which nevertheless incorporates the processes under study, allows for numerical experiments in which atmospheric chemistry and basic ABL dynamics are simultaneously solved at very low computational costs. A model that is similar to the one used here, including chemistry, is described by Vinuesa and Vilà-Guerau de Arellano (2005). Further development includes expanding the chemical module and taking the influence of specific humidity on the entrainment rate into account (Vilà-Guerau de Arellano et al., 2009). The chemical module is flexible and enables the use of different chemical schemes. In previous work it has mostly been used to represent the $\mathrm{O}_{3}-\mathrm{NO}_{\mathrm{x}}-\mathrm{VOC}-\mathrm{HO}_{\mathrm{x}}$ system that is typical for the Amazonian rain forest. The currently applied chemical scheme, which is based on van Stratum et al. (2012), is presented in Table 1. The scheme is expanded with a more detailed representation of $\mathrm{NO}_{\mathrm{x}}$ and $\mathrm{N}_{2} \mathrm{O}_{5}$ chemistry (Galmarini et al., 1997). The model acts as a 
Table 1. Chemical reaction scheme solved by the MXL model, based on van Stratum et al. (2012). $T$ is the absolute temperature in $\mathrm{K}$ and $\chi$ is the solar zenith angle. The unit of first-order reaction rate coefficients is $\mathrm{s}^{-1}$ and that of second-order reaction rate coefficients is $\mathrm{cm}^{3}$ molec $^{-1} \mathrm{~s}^{-1}$. Reactions (R15), (R24) and (R25) have more comprehensive expressions for their reaction rates ${ }^{1,2,3}$. For these expressions, $c_{\text {air }}$ and $c_{\mathrm{H}_{2} \mathrm{O}}$ are the concentrations in molec $\mathrm{cm}^{-3}$ for air and $\mathrm{H}_{2} \mathrm{O}$, respectively. Reactions (R1), (R5) and (R6) are photolysis reactions. MVK is the acronym of methyl vinyl ketone and REST stands for products and/or secondary fast reactions with reactants in the ambient air that are not specified.

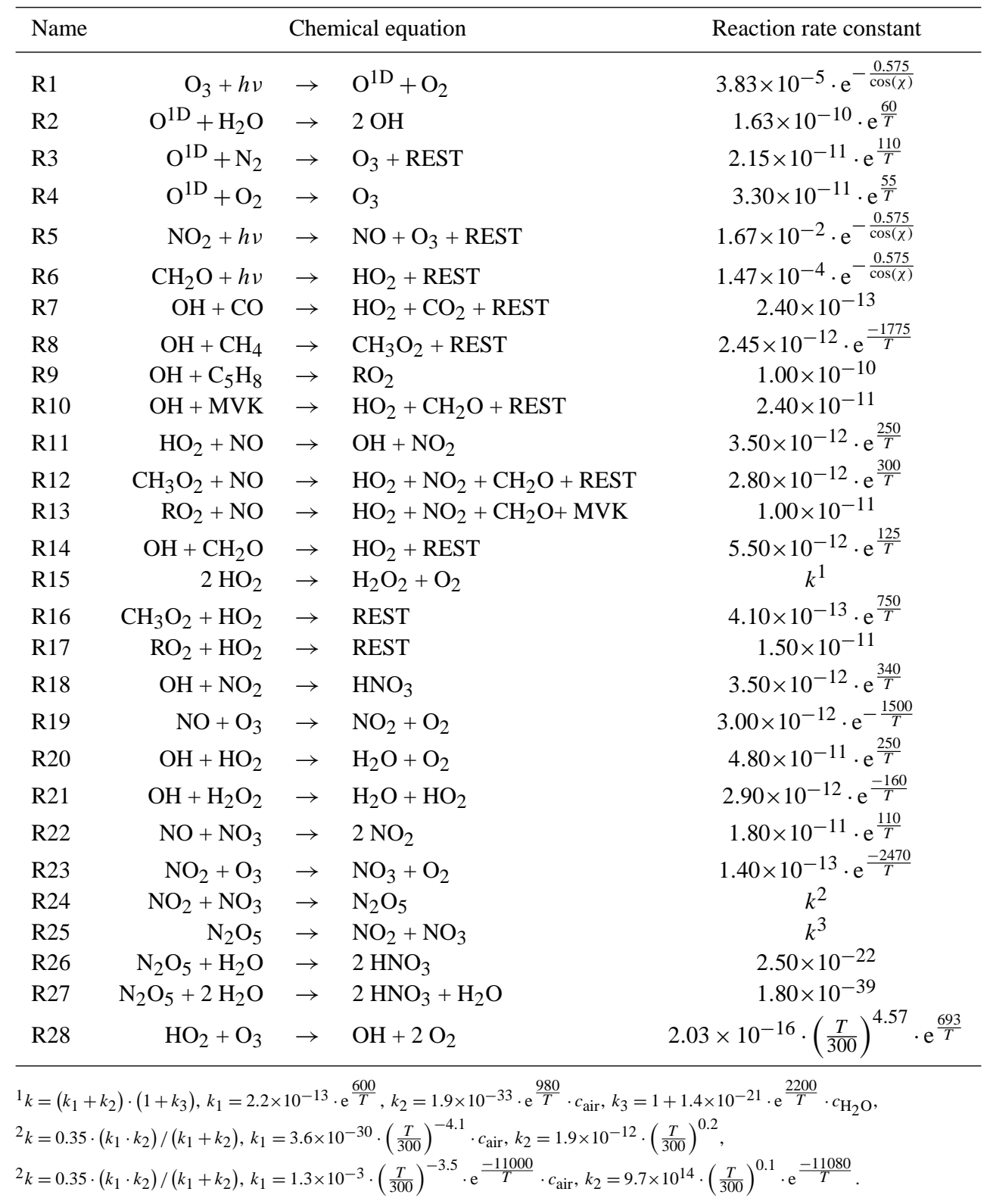

support for the observational data, enabling to study the evolution of the main properties of the boundary layer dynamics.

More information about the governing equations is given in Appendix A.

\subsection{LES model (DALES)}

To evaluate the use of radio soundings to obtain vertical profiles of temperature and moisture, numerical experiments were performed with the modified version 3.2 of the Dutch Atmospheric Large-Eddy Simulation (DALES) model (Heus et al., 2010). This model explicitly resolves dynamical (and selected chemical) processes in the boundary layer at grid resolutions finer than $100 \mathrm{~m}$. Therefore, the resulting data can be compared to local observations. In addition, DALES enables us to study how atmospheric flows that are induced by 

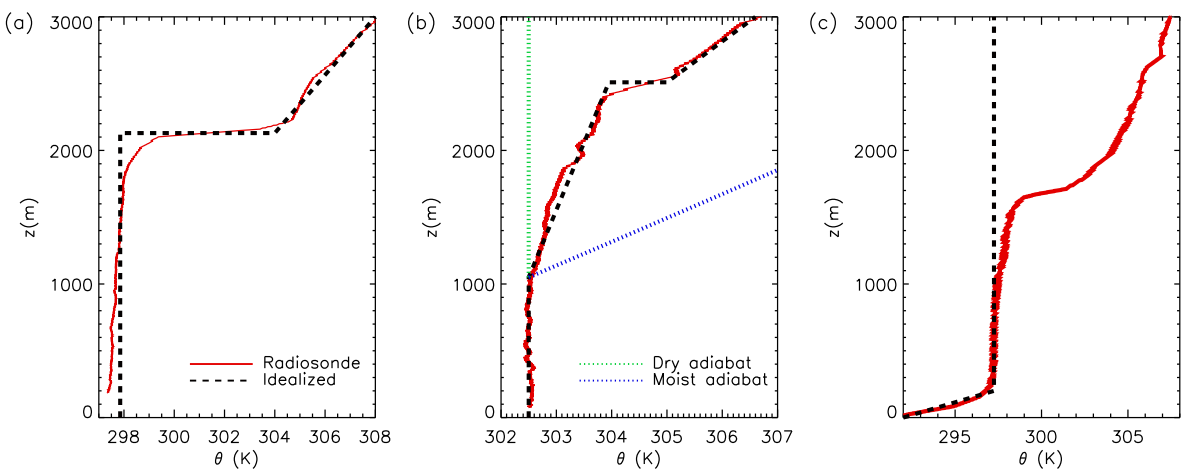

Fig. 1. Characteristic vertical potential temperature profiles for (a) a mixed layer, (b) a mixed layer topped with a conditionally unstable layer and (c) a stable boundary layer. In red an example from the radiosondes is presented, while in black an idealized profile is depicted. In (b) the profile of the potential temperature in the conditionally unstable layer is situated between the dry adiabat and the moist adiabat. In (c) a residual mixed layer from the previous day is present. The data is obtained at (a) 16:00 LT on 17 July, (b) 18:00 LT on 13 July and (c) 03:00 LT on 7 August.

heterogeneous surface forcings influence the distribution of both thermodynamic and chemical variables.

This specific LES model has first been used by Nieuwstadt and Brost (1986) and further developed and improved since (e.g., Cuijpers and Duynkerke, 1993; Dosio et al., 2003). Processes are explicitly resolved on scales larger than a set filter width and parametrized on the smaller scales at which the eddies contain less energy. The resolved equations are the filtered Navier-Stokes equations upon which the Boussinesq approximation is applied (Heus et al., 2010). Typically, the filter width is chosen such that over $90 \%$ of the turbulent energy is contained in the resolved scales. The subfilter-scale parametrization is based on the one-and-a-half-order closure assumption (Deardorff, 1973). Periodic boundary conditions are applied in the horizontal directions.

The version of DALES used for this study is modified to enable studies of ABL flows characterized by heterogeneous boundary conditions at the surface (Ouwersloot et al., 2011) and to generate local instantaneous vertical profiles of the chemical species mixing ratios and the dynamical variables. This allows for a comparison between radiosonde profiles and the profiles that are predicted by numerical experiments

\section{Results}

\subsection{Boundary layer prototypes}

Our interpretation of the radiosonde observations indicates that during HUMPPA-COPEC-2010 no clear trend due to synoptic influences is present and that the characteristics of the ABL significantly differ each day. Therefore, the boundary layer dynamics and their influence on atmospheric chemistry have to be analysed on a day-to-day basis. To support this analysis, it is convenient to have a first classification of the ABL dynamics during HUMPPA-COPEC-2010 and associate the radiosonde measurements to boundary layer prototypes. By performing this classification by inspection, the observations can thus be compared to the representations in combined chemistry-meteorology models. The prototypes are characterized by specific vertical profiles and the associated dynamical processes (e.g., Stull, 1988). During the campaign, three different prototypes were observed that correspond to the most representative vertical potential temperature profiles. Out of the 175 radiosondes 43 could not be classified by these prototypes, either due to instrumental errors or different (often transitional) characteristics in the observed vertical profiles. We select three potential temperature profiles from the radiosonde observations to describe their main characteristics. These profiles are similar to those of the virtual potential temperature, which are used for our classification. The profiles are presented in Fig. 1.

Figure 1a shows the potential temperature profile observed at 16:00 LT on 17 July. It is characterized by a relatively constant potential temperature with height, topped by a layer of a few hundred meters in which the vertical gradient of the potential temperature gradually increases. The location of the maximum potential temperature gradient marks the height of the boundary layer (Sullivan et al., 1998), in this case at approximately $2150 \mathrm{~m}$. From the top of the ABL, the potential temperature linearly increases with height, following its free tropospheric gradient. This increasing potential temperature profile indicates a region that is characterized by a stably stratified flow. The potential temperature is approximately equal in the entire boundary layer due to convective mixing. The jump in potential temperature at the top of the boundary layer, i.e. the thermal inversion, acts as a cap and limits the exchange of air between the ABL and the free troposphere. This measured profile is associated with the convective boundary layer that is usually formed by active convective turbulence during the day. As mentioned in Sect. 2.3, a commonly used approximation, the zeroth-order jump assumption (Garratt, 1992), assumes the inversion layer 
as infinitesimally small, resulting in a jump in the potential temperature at the top of the boundary layer. The resulting theoretical profile is plotted with dashed lines. This very common boundary layer prototype, especially in spring and summer, is evaluated further using the MXL model. ABL profiles of this kind are most clearly discernible during high pressure synoptic systems. During HUMPPA-COPEC-2010, the SMEAR II station was located in a high pressure region (Williams et al., 2011).

The profile of 18:00 LT on 13 July, as presented in Fig. 1b, is similar to the previously discussed one, but contains an extra layer. Until a height of $1050 \mathrm{~m}$ the potential temperature is again constant. However, in this case this mixed layer is topped with a conditionally unstable layer. The transition between the two layers is signified by a change in the potential temperature gradient by more than an order of magnitude. This type of ABL is frequently observed with active shallow cumulus (fair weather) clouds (Stull, 1988). The conditionally unstable layer is located between the mixed layer and the inversion layer and is characterized by an increase with height of the potential temperature that is stronger than the dry and weaker than the moist adiabatic lapse rate. The dry adiabatic lapse rate is defined as the increase of potential temperature that an unsaturated rising air parcel would experience under adiabatic conditions, while the moist adiabatic lapse rate describes this increase for a saturated rising air parcel. In short, the conditionally unstable layer acts as a turbulence suppressing stable layer for unsaturated air parcels and as a turbulence generating unstable layer for saturated air parcels. In the first case (clear air), this layer can be considered as part of the thermal inversion layer, while in the latter case (clouds) air parcels that enter the layer rise to its top. When this profile was observed, the humidity was too low to result in condensation (below $70 \%$ relative humidity) and clouds. If under such conditions condensation would have occurred for local air parcels in the conditionally unstable layer, the resulting clouds would become active and grow. Above the conditionally unstable layer, the thermal inversion is located at a height of $2500 \mathrm{~m}$. Above the inversion, the potential temperature rises according to the free tropospheric profile. The corresponding boundary layer prototype, shown by the black dashed line, is a mixed layer topped with a conditionally unstable layer.

The third radiosonde profile is depicted in Fig. 1c and is based on data obtained at 03:00 LT on 7 August. It shows a potential temperature that increases with height in a layer that reaches up to a few hundred meters above the surface. Aloft the potential temperature is relatively constant with height. On top, a thermal inversion at $1700 \mathrm{~m}$ and a free tropospheric profile are present. This data is characteristic for nocturnal stable boundary layers that are formed after an afternoon transition (e.g., Kaimal et al., 1976; Nieuwstadt and Brost, 1986). During the evening transition and at night, the air near the surface cools, driven by the emission of longwave radiation. This leads to stratification and a stable boundary

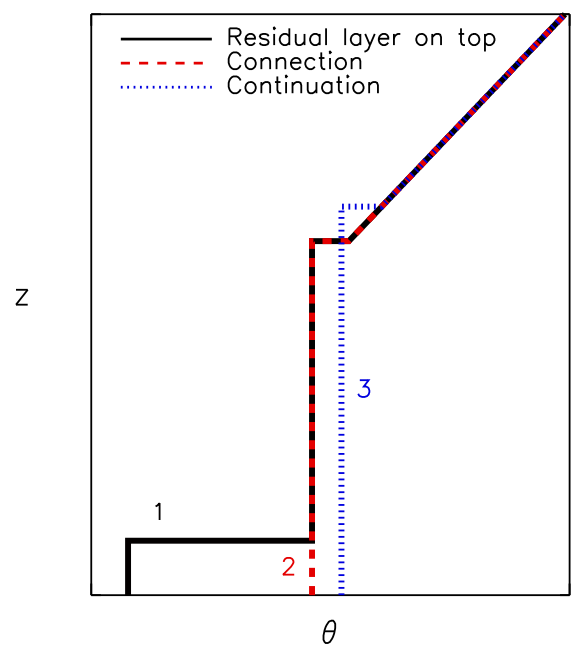

Fig. 2. Vertical potential temperature profiles during a transition from a mixed boundary layer topped with a residual boundary layer to a combined ABL. Initially (1) a shallow boundary layer develops under the influence of surface heat fluxes. When the potential temperatures in this layer and in the residual layer are equal, both layers connect (2). After both layers are connected, the combined ABL further develops as usual (3).

layer. A residual mixed layer from the previous day can be present above the stable boundary layer, as is the case in this example. However, this is not the case for all stable boundary layers and residual layers can disappear as time progresses (Kaimal et al., 1976). After sunrise, the Earth's surface warms and convective turbulence mixes the air. The stable boundary layer characteristics are then dissipated and a new convectively mixed boundary layer is formed. If a residual layer is still present, the new mixed layer develops until the potential temperature is equal in both layers. When this happens, buoyant thermals that originate at the surface enter the residual layer without passing through a stable atmospheric layer, a process called overshooting. It results in an almost instantaneous mixing of the new boundary layer with the air masses in the residual layer. From that moment on, mixed layer theory can be applied to study the evolution of the combined ABL. This process of connecting a shallow boundary layer with a residual layer is depicted in Fig. 2. Its impact will be analysed in more detail in Sect. 3.4, putting special emphasis on the evolution of the concentrations of the chemical species $\mathrm{NO}_{2}$ and $\mathrm{O}_{3}$.

An overview of the occurrence of all three boundary layer prototypes during HUMPPA-COPEC-2010 is given in Table 2 . Note that the radiosonde profiles in Fig. 1 are selected based on their unambiguous structure. In general, due to the instantaneous measurements, deviations of the radiosonde profile compared to the domain averaged profile occur, caused by different atmospheric processes. One of these, which is often overlooked, is the influence of land surface heterogeneity on the distribution of temperature, moisture 
Table 2. Occurrence of atmospheric boundary layer prototypes during HUMPPA-COPEC-2010 according to the radiosonde observations. Listed are the local daylight saving times $(\mathrm{UTC}+3)$. Times printed in bold correspond to radiosonde profiles used in this study. The three distinguished prototypes are the mixed layer, ML, the mixed layer topped with a conditionally unstable layer, UC, and a stable boundary layer, SL.

\begin{tabular}{|c|c|c|c|c|c|}
\hline \multirow{2}{*}{$\begin{array}{l}\text { Type } \\
\text { ML }\end{array}$} & \multicolumn{5}{|c|}{ Time of observation } \\
\hline & 09:00, $12 \mathrm{Jul}$ & 15:00, $12 \mathrm{Jul}$ & 21:00, $12 \mathrm{Jul}$ & 09:00, 13 Jul & 12:00, $13 \mathrm{Jul}$ \\
\hline & 12:00, $15 \mathrm{Jul}$ & 15:00, $15 \mathrm{Jul}$ & 09:00, 16 Jul & 12:00, 16 Jul & 15:00, $16 \mathrm{Jul}$ \\
\hline & 21:00, $16 \mathrm{Jul}$ & 22:00, $16 \mathrm{Jul}$ & 23:00, $16 \mathrm{Jul}$ & 00:00, $17 \mathrm{Jul}$ & 01:00, 17 Jul \\
\hline & 02:00, 17 Jul & 03:00, 17 Jul & 04:00, 17 Jul & 10:00, 17 Jul & 12:00, $17 \mathrm{Jul}$ \\
\hline & 14:00, 17 Jul & 16:00, 17 Jul & 18:00, $17 \mathrm{Jul}$ & 21:00, $17 \mathrm{Jul}$ & 09:00, $18 \mathrm{Jul}$ \\
\hline & 21:00, 18 Jul & 09:00, 19 Jul & 21:00, $19 \mathrm{Jul}$ & $12: 30,20 \mathrm{Jul}$ & $15: 15,21 \mathrm{Jul}$ \\
\hline & 21:00, $21 \mathrm{Jul}$ & 00:00, 22 Jul & 09:00, 22 Jul & 10:00, $22 \mathrm{Jul}$ & $12: 00,22 \mathrm{Jul}$ \\
\hline & 14:00, $22 \mathrm{Jul}$ & 18:00, 22 Jul & 21:00, 22 Jul & 03:00, 23 Jul & 09:00, 23 Jul \\
\hline & 12:00, $23 \mathrm{Jul}$ & 15:00, 23 Jul & 03:00, 24 Jul & 16:00, 24 Jul & 21:00, 24 Jul \\
\hline & 03:00, $25 \mathrm{Jul}$ & 12:00, 26 Jul & 21:00, 26 Jul & 09:00, 27 Jul & 12:00, $27 \mathrm{Jul}$ \\
\hline & 21:00, $27 \mathrm{Jul}$ & 12:00, 28 Jul & 15:00, $28 \mathrm{Jul}$ & 12:00, $29 \mathrm{Jul}$ & 14:00, 29 Jul \\
\hline & 16:00, $29 \mathrm{Jul}$ & 18:00, $29 \mathrm{Jul}$ & 21:00, $30 \mathrm{Jul}$ & 09:00, 1 Aug & 15:00, 2 Aug \\
\hline & 18:00, 2 Aug & 12:00, 3 Aug & 18:00, 3 Aug & 12:00, 4 Aug & 16:00, 4 Aug \\
\hline & $00: 00,5$ Aug & 09:00, 5 Aug & 12:00, 5 Aug & 10:00, 6 Aug & 12:00, 6 Aug \\
\hline & 14:00, 6 Aug & 16:00, 6 Aug & 18:00, 6 Aug & 21:00, 6 Aug & 12:00, 7 Aug \\
\hline & 15:00, 8 Aug & 09:00, 10 Aug & 18:00, $10 \mathrm{Aug}$ & & \\
\hline \multirow[t]{5}{*}{$\mathrm{UC}$} & $15: 00,13 \mathrm{Jul}$ & 18:00, 13 Jul & 12:00, $18 \mathrm{Jul}$ & $15: 45,18$ Jul & 15:00, $20 \mathrm{Jul}$ \\
\hline & 21:00, $20 \mathrm{Jul}$ & $13: 30,21 \mathrm{Jul}$ & 22:00, $21 \mathrm{Jul}$ & 23:00, $21 \mathrm{Jul}$ & 12:00, $24 \mathrm{Jul}$ \\
\hline & 15:00, $27 \mathrm{Jul}$ & 9:00, $30 \mathrm{Jul}$ & 15:00, $30 \mathrm{Jul}$ & 15:00, $31 \mathrm{Jul}$ & 21:00, $31 \mathrm{Jul}$ \\
\hline & 12:00, 1 Aug & 18:00, 1 Aug & 18:00, 4 Aug & 22:00, 4 Aug & 15:00, 5 Aug \\
\hline & 18:00, 5 Aug & 20:00, 5 Aug & 22:00, 5 Aug & 15:00, 7 Aug & 18:00, 8 Aug \\
\hline \multirow[t]{6}{*}{ SL } & 03:00, $12 \mathrm{Jul}$ & 03:00, 13 Jul & 21:00, 13 Jul & 03:00, 14 Jul & 09:00, 14 Jul \\
\hline & 16:00, 14 Jul & 03:00, 18 Jul & 03:00, 19 Jul & 04:00, 22 Jul & 05:00, $22 \mathrm{Jul}$ \\
\hline & 06:00, 22 Jul & 21:00, 25 Jul & 03:00, 26 Jul & 09:00, $26 \mathrm{Jul}$ & 03:00, 27 Jul \\
\hline & 21:00, 28 Jul & 22:00, $28 \mathrm{Jul}$ & 00:00, $29 \mathrm{Jul}$ & 02:00, $29 \mathrm{Jul}$ & 06:00, $29 \mathrm{Jul}$ \\
\hline & 08:00, $29 \mathrm{Jul}$ & 03:00, 1 Aug & 03:00, 2 Aug & 11:00, 4 Aug & 14:00, 4 Aug \\
\hline & 06:00, 6 Aug & 08:00, 6 Aug & 03:00, 7 Aug & $21: 00,8$ Aug & \\
\hline
\end{tabular}

and chemical species. To show that these deviations are realistic, Fig. 3 presents local instantaneous potential temperature profiles as generated by DALES. This simulation is based on the period between 12:00 and 15:00 LT of the MXL case that is treated in more detail in Sect. 3.2. The resolution of the domain is $50 \mathrm{~m}$ in the horizontal direction and $20 \mathrm{~m}$ in the vertical direction. The numerical grid spans $256 \times 256 \times 175$ cells in, respectively the $x, y$ and $z$ directions, resulting in a domain of $12.8 \mathrm{~km} \times 12.8 \mathrm{~km} \times 3.5 \mathrm{~km}$. Constant surface heat and moisture fluxes are imposed for $3 \mathrm{~h}$ after which the local instantaneous profiles are generated. The kinematic surface heat flux and moisture flux are $0.24 \mathrm{~K} \mathrm{~m} \mathrm{~s}^{-1}$ and $0.087 \mathrm{~g} \mathrm{~kg}^{-1} \mathrm{~m} \mathrm{~s}^{-1}$, corresponding to a sensible and latent heat flux of $295 \mathrm{~W} \mathrm{~m}^{-2}$ and $262 \mathrm{Wm}^{-2}$, respectively. In case of heterogeneous surface forcings, the domain is split into two patches in the $x$-direction, the $d r y$ and the wet patch. The kinematic surface heat flux is increased (decreased) by $0.04 \mathrm{~K} \mathrm{~m} \mathrm{~s}^{-1}$ and the kinematic surface moisture flux is decreased (increased) by $0.017 \mathrm{~g} \mathrm{~kg}^{-1} \mathrm{~m} \mathrm{~s}^{-1}$ for the dry (wet) patch. It appears from Fig. 3a that for the homogeneous surface forcings, even though the domain aver- aged profile is smooth (inset), the individual profiles slightly differ from each other and show more random behaviour due to the turbulent character of the ABL, i.e. local warm and cold parcels of air. As demonstrated by the blue dashed line, this can result in observed boundary layer heights that differ from the domain average. Figure $3 b$ shows that the differences between local instantaneous profiles are enhanced for heterogeneous surface forcings, especially over the patch with the higher sensible heat flux. This is due to the generated mesoscale circulations (Ouwersloot et al., 2011) in the ABL. These local differences should be kept in mind during the analysis of the radiosonde profiles.

\subsection{Diurnal evolution of the ABL}

To describe the boundary layer dynamics in greater depth, a specific day is selected, characterized by a boundary layer of the mixed layer type. The chosen day, 6 August 2010, was scheduled as an IOP, so multiple radio soundings were performed at relatively short time intervals (every $2 \mathrm{~h}$ ) during the day. The profiles of $\theta$ and $q$ show clear mixed layer prototype 

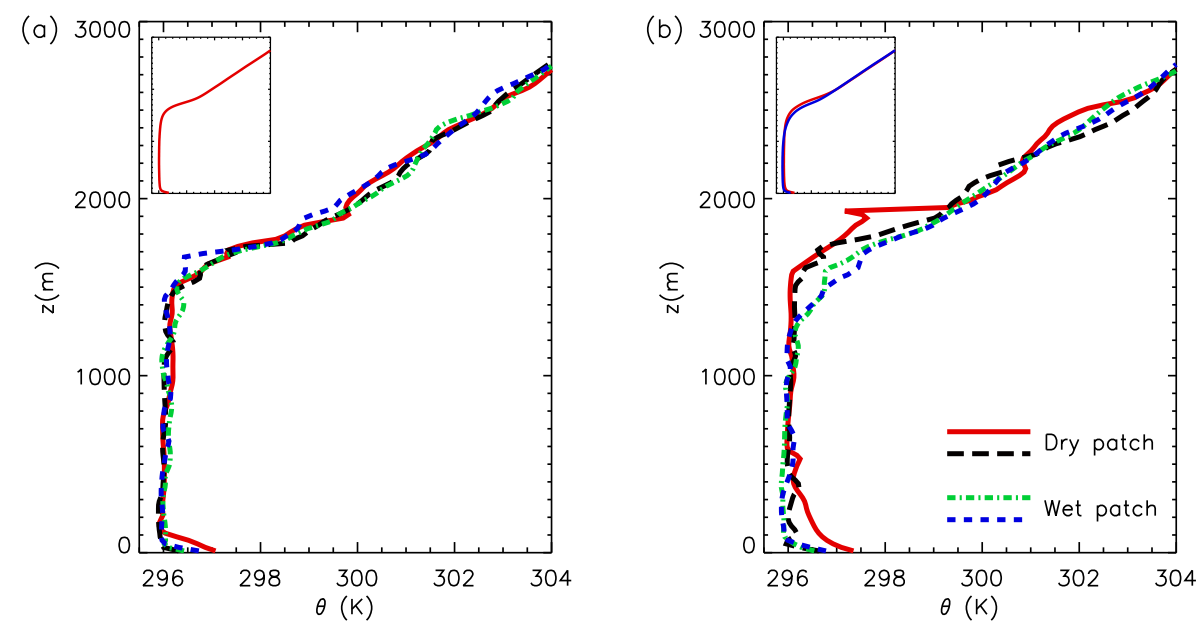

Fig. 3. Instantaneous and local potential temperature profiles as generated by DALES after $3 \mathrm{~h}$ of simulation. (a) shows 4 profiles at different locations, while its inset shows the instantaneous horizontal average over the total domain. In (b), 2 instantaneous profiles are displayed for the dry patch and 2 profiles for the wet patch. Its inset presents the horizontal averages over the dry and wet patch separately.

behaviour (Fig. 1a) for these soundings, enabling the analysis of the data using the MXL model. Most instruments for chemical observations were functioning and the weather conditions were typical. Therefore, chemical data is available for this day under conditions that are representative for the campaign. Closely related to our research questions, additional dynamical processes, which are often disregarded, are also important in interpreting atmospheric chemistry. These processes include advection of air masses, subsidence and the coupling of a dynamically evolving boundary layer with a residual layer aloft during the morning transition. The advection and subsidence are both related to forcings on the meso- and synoptic scale. Note that under typical conditions for which subsidence occurs (high pressure and temperature), the emissions of primary biogenic compounds are usually larger (e.g., Guenther et al., 2006; Yassaa et al., 2012). The advection is assumed to have an equal impact on both the boundary layer and the free troposphere.

Figure 4 shows the time evolution of the boundary layer dynamics as observed by the radiosondes. The vertical profiles of potential temperature and specific humidity are displayed in Fig. 4a and b, respectively. For clarity, only four profiles (at 06:00, 10:00, 14:00 and 18:00 LT) are presented out of the eight available ones (at 06:00, 08:00, 10:00, 12:00, 14:00, 16:00, 18:00 and 21:00 LT). We omit the radiosonde profiles near the surface (until 100-300 m) due to the poor reception of the sonde data by the antenna of the ground station if the sonde is near the surface. At higher altitudes, the signal is less perturbed and data is received regularly. In Fig. 4c, the evolution of the boundary layer height is presented. Boundary layer heights are denoted by asterisks, while the top of the residual layer (in the morning) is denoted by circles.

To initialize the MXL model, the vertical profiles of the potential temperature and specific humidity for an initial point in time are applied. For this study, the residual layer in the observations at 08:00 LT is chosen as an initial profile. Since the residual layer is much deeper than the underlying shallow mixed layer ( $975 \mathrm{~m}$ and $150 \mathrm{~m}$, respectively) and both layers connect and mix within the first hours of the day (between 08:00 and 10:00 LT), considering the residual layer as a start of a new mixed layer seems a valid approximation.

The radiosonde observations are also used to derive the effects of large scale subsidence (descending air) and advection. These effects can not be observed directly, but by using the radiosonde observations as a reference for the predicted evolution of the ABL dynamics, one can obtain a first order estimation. To determine the subsidence velocity, the observed growth of the boundary layer height is compared to the modelled evolution velocity due to entrainment. The subsidence velocity is calculated as the difference between these two velocities, as expressed by Eq. (A4). To derive the contribution of the horizontal advection of air masses we take a different approach. The horizontal advection of air, with different dynamical and/or chemical properties, results in an increase or decrease in the mixed layer averaged scalars. In our model this rate of change is considered to be constant in time. Therefore, a difference between the observed and modelled scalar values that increases linearly in time is considered to be caused by advection. For the case study we find that the advection of cooler air is of importance for temperature (with a cooling rate of $0.108 \mathrm{~K} \mathrm{~h}^{-1}$ resulting in a maximum difference of $1.5 \mathrm{~K}$ ), whereas there is no significant contribution of advection to humidity. This approach cannot be directly applied to the advection of chemical species, since the free tropospheric concentrations are unknown. In addition, differences can be caused by unaccounted chemical pathways. 

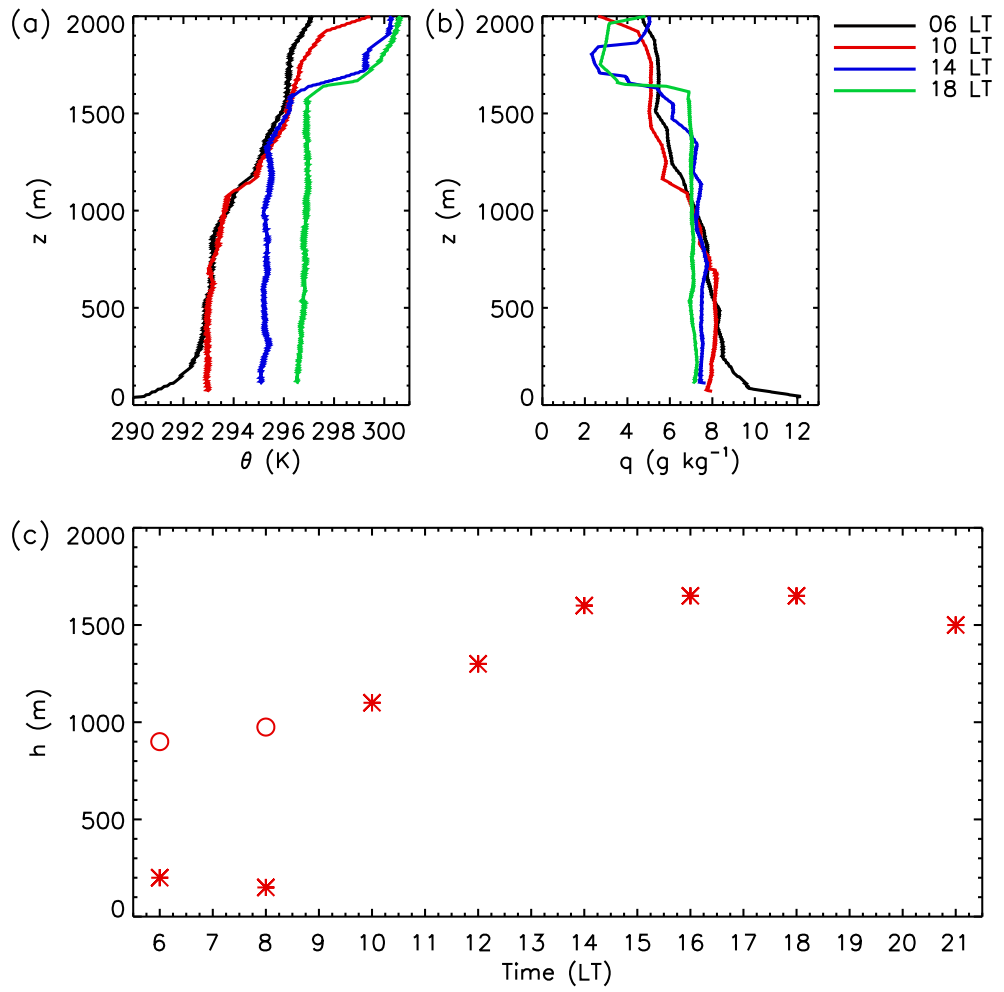

Fig. 4. Evolution of the vertical profiles of (a) the potential temperature and (b) specific humidity as measured by radiosondes on 6 August $2010(06: 00,10: 00,14: 00$ and 18:00 LT). In (c) the evolution of the boundary layer height is presented, derived from all vertical profiles observed during that day. Asterisks indicate the height of the boundary layer, while circles represent the height of the residual layer in the morning. The shallow boundary layer connects with the residual layer between 08:00 and 10:00 LT.

The prescribed sensible and latent heat fluxes in the MXL model are determined by fitting sinusoids through the observed fluxes, as shown in Fig. 5a. The complete set of initial conditions and forcings is presented in Table 3. In Fig. 5b-d, the simulated evolutions of the main dynamical ABL characteristics are shown together with the observations. This shows that the model reproduces the radiosonde observations for temperature, moisture and boundary layer heights well. Until approximately 17:00 LT, entrainment most strongly influences the ABL height development, resulting in a deepening ABL. When the boundary layer reaches its maximum height of $1740 \mathrm{~m}$, the subsidence velocity for that height is equal in magnitude as the entrainment velocity. By that time the entrainment process is still very active, as the driving heat fluxes are still greater than $50 \%$ of their maximum values. Since the surface sensible and latent heat fluxes continuously decrease after 14:00 LT, the entrainment fluxes weaken as well. Consequently, after 17:00 LT the subsidence becomes stronger than the rate of the boundary layer growth by entrainment and the ABL height decreases with time. This can be seen in Fig. 5b. The potential temperature, shown in Fig. 5c, increases with time due to surface fluxes and the related entrainment of relatively warm air from the free troposphere. After sunset, the surface buoyancy flux becomes negligible and, as a result, the convective boundary layer type (Fig. 1a) is not longer applicable. A stable boundary layer appears with a residual layer aloft (Fig. 1c). During the whole day, the advection of relatively cool air results in a decrease of the potential temperature. After 18:00 LT this effect is stronger than the heating effect of the surface fluxes and entrainment, explaining the temperature decline. As shown by the time evolution in Fig. 5d, the specific humidity remains approximately constant, since the effects of the surface moisture flux and the entrainment of relatively dry air cancel each other $\left(\frac{\partial\langle q\rangle}{\partial t} \approx 0\right)$.

To determine the importance of advection and subsidence, four different cases have been simulated. The three cases other than the previously derived standard MXL case differ by having the subsidence and/or advection disabled. We omit the effect of subsidence by setting $\operatorname{Div}_{U}=0 \mathrm{~s}^{-1}$ and the horizontal advection of air with a different temperature by setting $\operatorname{Adv}_{\theta}=0 \mathrm{Ks}^{-1}$ (Appendix A). First we discuss the impact of subsidence. From Fig. 6a we find that subsidence is significant for the boundary layer height development on 6 August 2010. In the cases without subsidence the boundary layer grows like a standard convectively mixed boundary layer until approximately 20:00 LT. Subsequently, the surface heat flux does not remain positive and the growth 

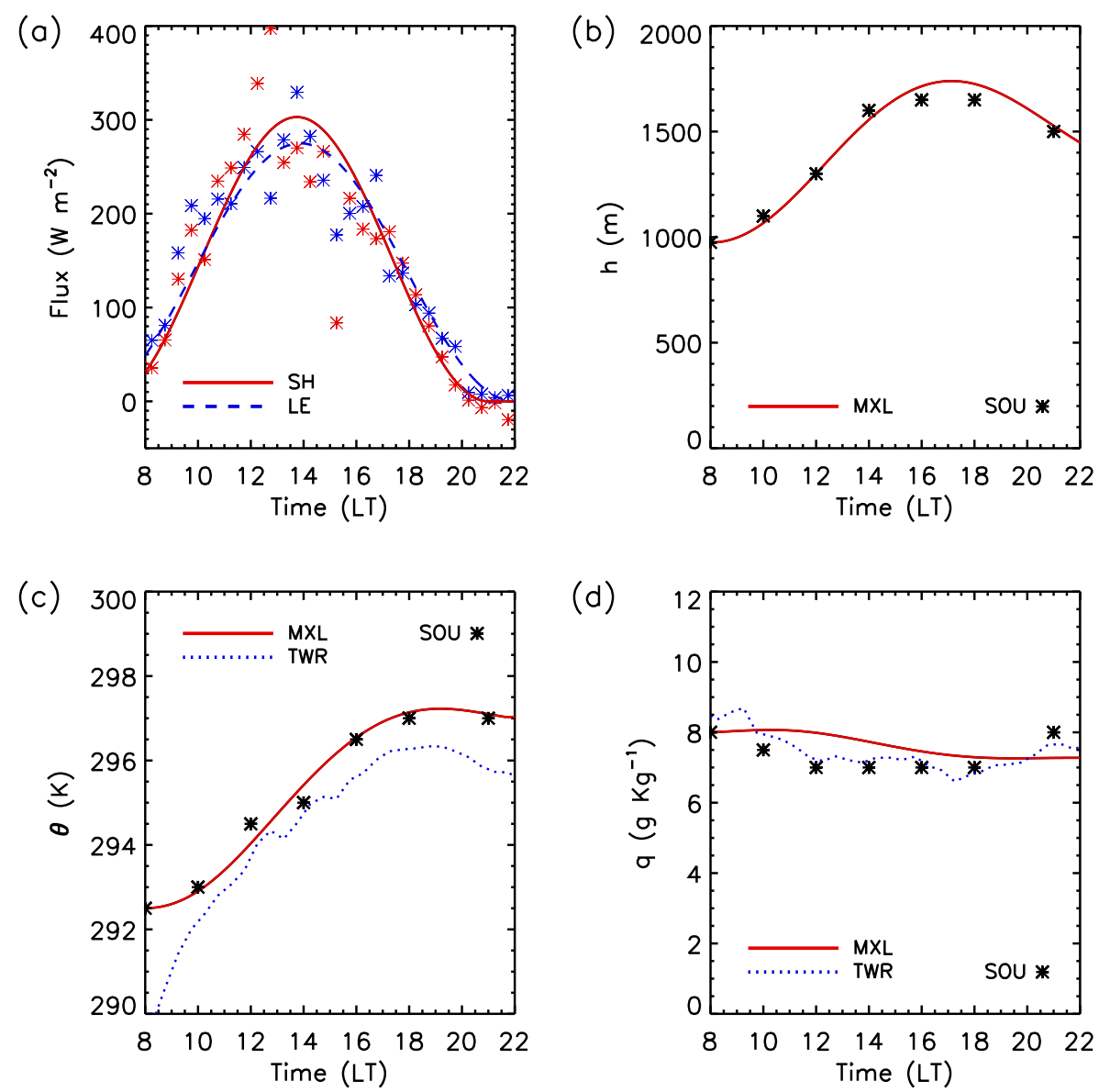

Fig. 5. Applied surface forcings (a) and simulated evolution of ABL characteristics (b, c, d) by the MXL model. The ABL characteristics include the boundary layer height (b), potential temperature (c) and specific humidity (d). In (a), the lines represent the sensible heat flux, SH, and latent heat flux, LE, surface forcings applied to the model and the asterisks represent the corresponding observations from the tower. In $(\mathbf{b}, \mathbf{c}, \mathbf{d})$, solid red lines depict model results and the asterisks symbolize radiosonde observations. Tower observations (TWR) are expressed by dotted blue lines.
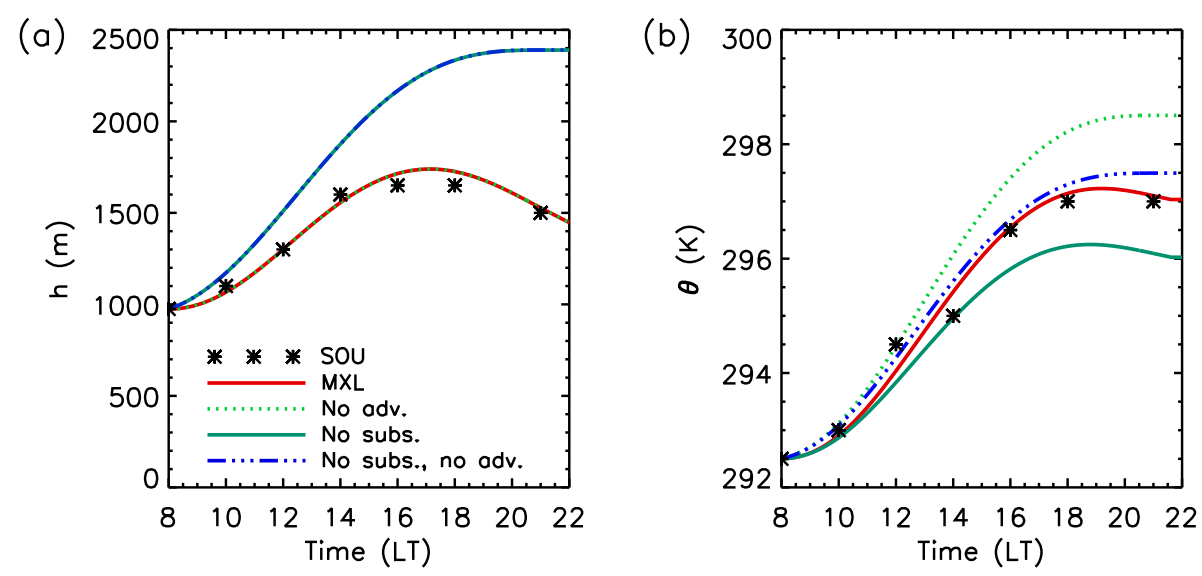

Fig. 6. Different evolutions of (a) the ABL height and (b) the potential temperature predicted by the MXL model. Subsidence and advection are separately enabled and disabled for the different numerical experiments, resulting in four cases. The results are compared to radiosonde observations, SOU. The most accurate case, with advection and subsidence enabled, is labelled MXL. Note that the advection does not significantly affect the boundary layer height evolution. Therefore, the curves are superposed in (a) for the cases with and without prescribed advection. 
Table 3. Overview of the prescribed initial and boundary conditions. Presented are the initial values (subscript 0) for $h, \theta$ and $q$, the initial differences between the free troposphere and boundary layer (additional prefix $\Delta$ ) and the free tropospheric gradients (denoted by $\gamma$ ) for $\theta$ and $q$, the surface fluxes (subsript s), the large scale divergence, $\operatorname{Div}_{U}$, and the advection of heat, $\operatorname{Adv}_{\theta}$, and moisture, $\operatorname{Adv}_{q}$, for the MXL model. The time, $t$, is expressed in hours local daylight saving time. $\rho=1.2 \mathrm{~kg} \mathrm{~m}^{-3}, c_{p}=1.0 \times 10^{3} \mathrm{Jkg}^{-1} \mathrm{~K}^{-1}$ and $L_{v}=2.5 \times 10^{6} \mathrm{~J} \mathrm{~kg}^{-1}$. The MXL model is run for $14 \mathrm{~h}$.

\begin{tabular}{lc}
\hline Property & Value \\
\hline$t_{0}(\mathrm{~h})$ & 8 \\
$h_{0}(\mathrm{~m})$ & 975 \\
$\operatorname{Div}_{U}\left(\mathrm{~s}^{-1}\right)$ & $1.5 \times 10^{-5}$ \\
\hline$\langle\theta\rangle_{0}(\mathrm{~K})$ & 292.5 \\
$\Delta \theta_{0}(\mathrm{~K})$ & 0.5 \\
$\gamma_{\theta}\left(\mathrm{K} \mathrm{m}^{-1}\right)$ & $4.7 \times 10^{-3}$ \\
$\operatorname{Adv}_{\theta}\left(\mathrm{K} \mathrm{s}^{-1}\right)$ & $-3 \times 10^{-5}$ \\
\hline$q_{0}\left(\mathrm{~g} \mathrm{~kg}^{-1}\right)$ & 8 \\
$\Delta q_{0}\left(\mathrm{~g} \mathrm{~kg}^{-1}\right)$ & -0.5 \\
$\gamma_{q}\left(\mathrm{~g} \mathrm{~kg}^{-1} \mathrm{~m}^{-1}\right)$ & 0 \\
$\operatorname{Adv}_{q}\left(\mathrm{~g} \mathrm{~kg}^{-1} \mathrm{~s}^{-1}\right)$ & $310\left(\frac{1}{2}-\frac{1}{2} \cos \left(2 \pi \frac{t-6.5}{14.5}\right)\right)$ \\
\hline$\rho c_{p} \overline{w^{\prime} \theta^{\prime}}{ }_{\mathrm{s}}\left(\mathrm{W} \mathrm{m}^{-2}\right)$ & $275\left(\frac{1}{2}-\frac{1}{2} \cos \left(2 \pi \frac{t-5.75}{16.25}\right)\right)$ \\
$\rho L_{v} \overline{w^{\prime} q^{\prime}}{ }_{\mathrm{s}}\left(\mathrm{W} \mathrm{m}^{-2}\right)$ &
\end{tabular}

stops. Since this layer is no longer actively mixed, it remains as a residual layer on top of the stable nocturnal boundary layer. When subsidence occurs, the boundary layer growth slows down, resulting in lower ABL heights. As mentioned earlier, after 18:00 LT the boundary layer height decreases as the subsidence is stronger than the ABL height increase due to entrainment and the ABL becomes shallower. The rate of boundary layer height decrease reaches its maximum when entrainment ceases. The subsidence does not influence the incoming heat fluxes, but does result in shallower boundary layers. Therefore, subsidence promotes a warmer ABL. This is discernible in Fig. 6 b.

Figure 6a shows that the advection of relatively cold air from other regions does not affect the boundary layer height evolution. The reason is that the advection is assumed to be equal in the free troposphere and the boundary layer, hence the strength of the thermal inversion remains virtually unaltered. The difference in potential temperature due to advection increases linearly in time up to $1.5 \mathrm{~K}$ after the $14 \mathrm{~h}$ of simulated time, as depicted in Fig. 6b. During the day, the impacts of advection and subsidence on the potential temperature roughly cancel in the case under study. Therefore, if both effects are ignored, the resulting potential temperature evolution is similar to that when both effects are concurrently considered. Our results indicate that the effects of both sub- sidence and horizontal advection are important to take into account.

\subsection{Importance of the ABL height representation for atmospheric chemistry}

After determining the evolution of the ABL dynamics, we study how it influences the mixing ratios of reactive species. Here we focus on the importance of a correct representation of the boundary layer height. Note that we solely study the primary effect of the boundary layer height evolution on the mixing ratio of chemical species, i.e. the ratios between surface exchange and mixing height (first term on the r.h.s. of Eq. A1). To prevent biases due to a combination of dilution and entrainment (e.g., Vilà-Guerau de Arellano et al., 2011), the initial mixing ratios are set equal in the boundary layer and the free troposphere. Two atmospheric chemistry cases are evaluated to show the impacts of the ABL dynamics and surface emissions depending on the region under study. For the first case the initial conditions and surface forcings are based on boreal conditions, while a second case, with a higher isoprene emission and initial mixing ratio, is formulated to contrast the boreal forest to the tropical Amazon rainforest chemical conditions. Especially the initial mixing ratios can significantly affect the chemistry. The initial mixing ratios, in ppbv, and the emissions at the surface, in $\mathrm{mg} \mathrm{m}^{-2} \mathrm{~h}^{-1}$, are set to 0 , except for the values listed in Table 4.

We designed three different numerical experiments: a "realistic" case, a constant case and a case that considers the residual layer part of the free troposphere (by ignoring the residual layer). The three corresponding boundary layer height evolutions are shown in Fig. 7a. The first case corresponds with that described in the previous section, though complemented by the chemistry calculations. Thus the boundary layer height evolution is equal to the one presented above, which represents the observations. The second case represents a boundary layer with a constant height, mimicking the performance of chemical box models. For the third case, the initial profile is taken from the radiosonde at 08:00 LT, but the difference between the residual layer and the free troposphere aloft is ignored. Therefore, this layer is considered to be part of the free troposphere only and the prescribed initial mixed layer conditions and the free tropospheric gradients both change. The effect of subsidence is not considered for this situation. The altered settings for this case are listed in Table 5.

In Fig. $7 b$ the resulting evolutions of the hydroxyl radical $(\mathrm{OH})$ mixing ratio are presented for the boreal conditions. Since the emissions of isoprene $\left(\mathrm{C}_{5} \mathrm{H}_{8}\right)$ are relatively low, and its background concentration is negligible, the depletion of $\mathrm{OH}$ is governed by other chemical species (especially $\mathrm{CO}$ ). As we prescribe uniform initial profiles in the ABL and the free troposphere and neglect surface exchanges for these other chemical species, the resulting time evolutions of $\mathrm{OH}$ 
Table 4. Overview of the prescribed initial mixing ratios (ppbv) and the emissions at the surface $\left(\mathrm{mg} \mathrm{m}^{-2} \mathrm{~h}^{-1}\right)$ of the reactive species for Sect. 3.3 for both boreal and Amazonian chemical conditions. Not listed are the values for species without emissions and zero initial mixing ratio and the values for $\mathrm{O}_{2}$ and $\mathrm{N}_{2}$. These latter two species have constant mixing ratios of $2 \times 10^{8}$ and $8 \times 10^{8}$ ppbv, respectively. For the emissions, the functions $f_{1}=\left(\frac{1}{2}-\frac{1}{2} \cos \left(2 \pi \frac{t-4}{18}\right)\right)$ and $f_{2}=\sin \left(2 \pi \frac{t-4}{18}\right)$ can be used with $t$ in hours local daylight saving time. The conversion factors for the $\mathrm{NO}$ and $\mathrm{C}_{5} \mathrm{H}_{8}$ emissions from ppbv ms ${ }^{-1}$ to $\mathrm{mg} \mathrm{m}^{-2} \mathrm{~h}^{-1}$ are 4.4 and 10 , respectively.

\begin{tabular}{lccccccccc}
\hline & $\mathrm{O}_{3}$ & $\mathrm{NO}$ & $\mathrm{NO}_{2}$ & $\mathrm{CH}_{4}$ & $\mathrm{CH}_{2} \mathrm{O}$ & $\mathrm{MVK}$ & $\mathrm{C}_{5} \mathrm{H}_{8}$ & $\mathrm{CO}$ & $\mathrm{H}_{2} \mathrm{O}_{2}$ \\
\hline Boreal chemical conditions & & & & & & & & & \\
Initial mixing ratio & 24.5 & 0.07 & 0.224 & 1759 & 0.171 & 0.0877 & 0.17 & 101.95 & 0.0266 \\
Prescribed emission & 0 & $1.76 \times 10^{-2} f_{1}$ & 0 & 0 & 0 & 0 & $0.1 f_{2}$ & 0 & 0 \\
\hline Amazonian chemical conditions & & & & & & & & & \\
Initial mixing ratio & 10 & 0 & 1 & 1724 & 0 & 1.3 & 2 & 124 & 0 \\
Prescribed emission & 0 & $2.2 \times 10^{-3}$ & 0 & 0 & 0 & 0 & 6.5 & 0 & 0 \\
\hline
\end{tabular}
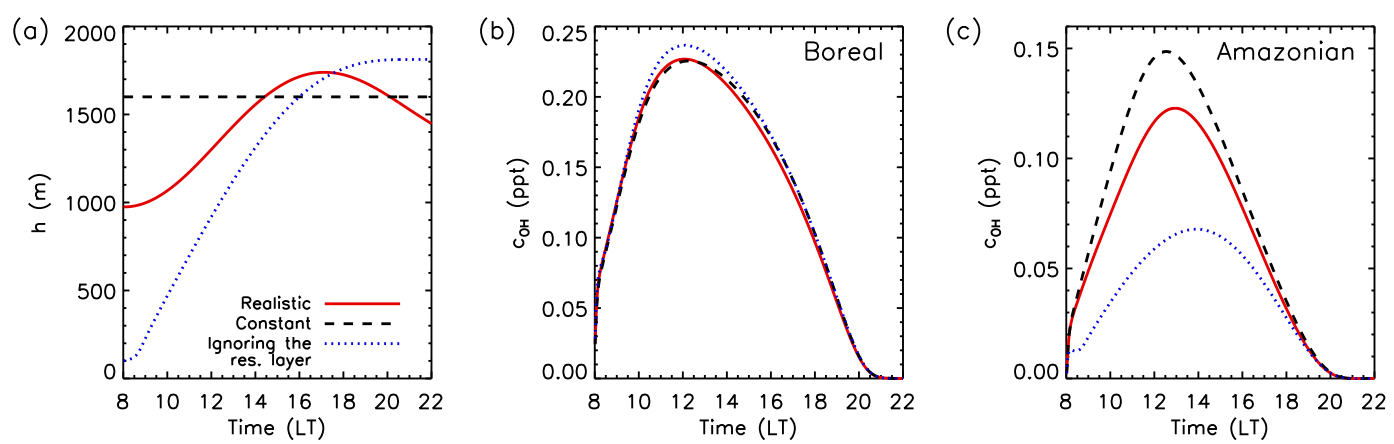

Fig. 7. Impact of (a) the ABL height development on $(\mathbf{b}, \mathbf{c})$ the mixing ratio of $\mathrm{OH}$. Panels $(\mathbf{b})$ and (c) present the results for initial chemical conditions and surface exchanges typical for boreal (as in HUMPPA-COPEC-2010) and Amazonian (Ouwersloot et al., 2011) conditions, respectively. Three cases are presented: (1) the boundary layer height as determined by the MXL model for 6 August 2010, (2) a constant boundary layer height and (3) a boundary layer height as determined by the MXL model if the residual layer would be considered as part of the free troposphere.

Table 5. Overview of the altered initial and boundary conditions for the case in which the residual layer is ignored compared to the standard case in Table 3. Listed are initial values (subscript 0 ), free tropospheric gradients, $\gamma$, and the large scale velocity divergence, $\operatorname{Div}_{U}$.

\begin{tabular}{lc}
\hline Property & Value \\
\hline$h_{0}(\mathrm{~m})$ & 100 \\
$\operatorname{Div}_{U}\left(\mathrm{~s}^{-1}\right)$ & 0 \\
\hline$\langle\theta\rangle_{0}(\mathrm{~K})$ & 290 \\
$\Delta \theta_{0}(\mathrm{~K})$ & 1 \\
$\gamma_{\theta}\left(\mathrm{K} \mathrm{m}^{-1}\right)$ & $6.3 \times 10^{-3}$ \\
\hline$q_{0}\left(\mathrm{~g} \mathrm{~kg}^{-1}\right)$ & 9 \\
$\Delta q_{0}\left(\mathrm{~g} \mathrm{~kg}^{-1}\right)$ & 0 \\
$\gamma_{q}\left(\mathrm{~g} \mathrm{~kg}^{-1} \mathrm{~m}^{-1}\right)$ & $-2.2 \times 10^{-3}$ \\
\hline
\end{tabular}

are very similar. As presented in Fig. 7c, it becomes different for our case with Amazonian conditions. In this case, the initial concentration and the emission of isoprene are higher and the depletion of $\mathrm{OH}$ due to isoprene is significant. During the first six hours of simulated time, if the emitted isoprene is distributed over a smaller mixing volume, the isoprene concentrations become higher and, consequently, the depletion of $\mathrm{OH}$ is enhanced. The constant boundary layer height case, which has the larger mixing volume, therefore starts with the highest $\mathrm{OH}$ concentration. The ABL height and $\mathrm{OH}$ mixing ratio are lowest for the case that ignores the residual layer. Due to the additionally produced secondary reactants (e.g. through $\mathrm{RO}_{2}$ ) this effect remains even after the boundary layers reach the same height for two cases. Because of this non-linear effect, the $\mathrm{OH}$ mixing ratio remains highest in the case with the constant boundary layer height and lowest in the case where the influence of the residual layer is ignored. Our findings show that for an adequate model representation of atmospheric chemistry in the boundary layer, it is important to represent the boundary layer height evolution throughout the day. This holds especially for cases in which emitted chemical compounds significantly affect 
Table 6. The prescribed initial values (subscript 0) and free tropospheric gradients, $\gamma$, for three different numerical experiments with the MXL model. The initial time, $t_{0}$, is expressed in hours local daylight saving time and the runtime of the model is expressed by $t_{\text {run }}$ in hours.

\begin{tabular}{lccc}
\hline Property & Standard run & Lower layer & Connected layers \\
\hline$t_{0}(\mathrm{~h})$ & 8 & 8 & 9.5 \\
$t_{\text {run }}(\mathrm{h})$ & 14 & 1.5 & 12.5 \\
$h_{0}(\mathrm{~m})$ & 975 & 150 & 1027 \\
\hline$\langle\theta\rangle_{0}(\mathrm{~K})$ & 292.5 & 290.0 & 292.73 \\
$\Delta \theta_{0}(\mathrm{~K})$ & 0.5 & 2.0 & 0.73 \\
$\gamma_{\theta}\left(\mathrm{K} \mathrm{m}^{-1}\right)$ & $4.7 \times 10^{-3}$ & $1.5 \times 10^{-3}$ & $4.7 \times 10^{-3}$ \\
\hline$q_{0}\left(\mathrm{~g} \mathrm{~kg}^{-1}\right)$ & 8 & 9 & 8.06 \\
$\Delta q_{0}\left(\mathrm{~g} \mathrm{~kg}^{-1}\right)$ & -0.5 & 0 & -0.91 \\
$\gamma_{q}\left(\mathrm{~g} \mathrm{~kg}^{-1} \mathrm{~m}^{-1}\right)$ & $-2.7 \times 10^{-3}$ & $-2.2 \times 10^{-3}$ & $-2.7 \times 10^{-3}$ \\
\hline
\end{tabular}

the chemical conditions. Note that the differences in $\mathrm{OH}$ between different boundary layer height representations can be over a factor 2 , which is similar to the differences seen between observed and modelled $\mathrm{OH}$ (Butler et al., 2008). In previous work, changes in chemical mechanisms were proposed to help explain these differences (Lelieveld et al., 2008).

\subsection{Representation of the morning transition}

As discussed in Sect. 3.1, in the early morning a residual mixed layer from the previous day is frequently observed above the stable boundary layer and the shallow boundary layer that follows when convection starts. Due to the initially weak surface heat fluxes, the potential temperature in the shallow boundary layer increases until it is similar to the residual mixed layer (in our case around 09:30 LT). Then both layers merge and become one mixed boundary layer, as illustrated in Fig. 2. In the MXL model this merging of two atmospheric layers into one is instantaneous. However, in reality it can take some time due to inhomogeneous $\mathrm{ABL}$ conditions and the time it takes for thermals to rise from the surface to the top of the residual layer. In this section we will show that this process can explain specific patterns in the chemistry observations during the morning transition. Note that these numerical experiments do not aim for a perfect representation of the boreal atmospheric chemistry, for example by not accounting for dry deposition (Ganzeveld et al., 2002), though demonstrate that this merger of two atmospheric layers is an important process that may explain certain features in the observations of chemical species in the morning.

Three numerical experiments were designed. The first, the standard case, corresponds to that previously defined in Sect. 3.2, except for the chemical conditions. This case assumes the residual layer to be part of the mixed layer. The second experiment, the lower layer, is based on the initial shallow boundary layer. This corresponds to situation (1) in Fig. 2. The initial values for potential temperature, spe- cific humidity and ABL height are again obtained from the radiosonde observation of 08:00 LT. This numerical experiment is run for $1.5 \mathrm{~h}$. After that the buoyant thermals that originate from the shallow boundary layer enter the residual layer and the two layers mix almost instantaneously, resulting in situation (2) in Fig. 2. The third numerical experiment represents the ensuing combined mixed layer. This case is referred to as connected layers and is labelled situation (3) in Fig. 2. The dynamical settings that differ per numerical experiment are listed in Table 6 for all three cases. Dynamical settings not mentioned explicitly are equal to the case prescribed in Sect. 3.2 and Table 3. The prescribed emissions and initial mixing ratios, presented in Table 7 if non-zero, are chosen such that the observations of the isoprene, $\mathrm{NO}$, $\mathrm{NO}_{2}$ and $\mathrm{O}_{3}$ mixing ratios are reproduced.

The observed and modelled mixing ratios of $\mathrm{NO}_{2}$ and $\mathrm{O}_{3}$ are presented in Fig. 8a and b, respectively. The time evolution of NO (not shown) has similar features as that of $\mathrm{NO}_{2}$. The observations show that in the early morning (until 9:30 LT) the $\mathrm{NO}_{2}$ mixing ratio rises quickly. This is due to the emission of $\mathrm{NO}_{\mathrm{x}}$ into the shallow boundary layer. Subsequently, the two atmospheric layers merge. Since the air in the residual layer has lower mixing ratios of NO and $\mathrm{NO}_{2}$, the mixing ratios in the combined mixed layer are lower than the mixing ratios in the previous shallow boundary layer. Because in reality the conditions of the ABL are not fully horizontally homogeneous, this mixing does not occur simultaneously everywhere, resulting in a transition that takes approximately one hour. After the mixing of the two layers, the $\mathrm{NO}_{\mathrm{x}}$ contributions of emission and entrainment are still positive, but are distributed over a larger mixing volume. Therefore, their impact becomes weaker and, due to chemical destruction by $\mathrm{OH}$, the $\mathrm{NO}_{2}$ mixing ratio slightly decreases with time. The morning peak in $\mathrm{NO}_{2}$ can not be reproduced by the MXL model if only one numerical experiment is performed. However, by combining two numerical experiments, one for the shallow boundary layer and one for the final combined mixed layer, this peak can 
Table 7. The prescribed initial mixing ratios (ppbv) and the emissions at the surface $\left(\mathrm{mg} \mathrm{m}^{-2} \mathrm{~h}^{-1}\right)$ of the reactive species for the numerical

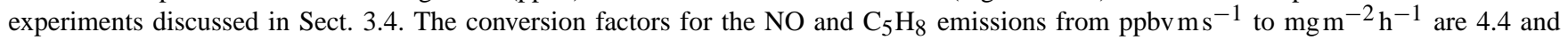
10, respectively. The initial conditions are listed for the boundary layer, BL, and the atmospheric layer aloft, TOP. Maximum emissions are denoted by EM and emission patterns by PAT. COS corresponds to an emission of $\operatorname{EM}\left(\frac{1}{2}-\frac{1}{2} \cos \left(2 \pi \frac{t-4}{18}\right)\right)$ and SIN to an emission of EMsin $\left(2 \pi \frac{t-4}{18}\right)$. Not listed are the values for species without emissions and zero initial mixing ratio and those for $\mathrm{CH}_{4}, \mathrm{O}_{2}$ and $\mathrm{N}_{2}$. These latter three species have constant mixing ratios of $1759,2 \times 10^{8}$ and $8 \times 10^{8}$ ppbv, respectively.

\begin{tabular}{lcccccccc}
\hline & $\mathrm{O}_{3}$ & $\mathrm{NO}$ & $\mathrm{NO}_{2}$ & $\mathrm{CH}_{2} \mathrm{O}$ & $\mathrm{MVK}$ & $\mathrm{C}_{5} \mathrm{H}_{8}$ & $\mathrm{CO}$ & $\mathrm{H}_{2} \mathrm{O}_{2}$ \\
\hline \multicolumn{2}{l}{ Standard run } & & & & & & & \\
BL: & 24.5 & 0.07 & 0.224 & 0.171 & 0.0877 & 0.170 & 101.95 & 0.0266 \\
TOP: & 52.0 & 0.10 & 0.500 & 0.000 & 0.0000 & 0.000 & 101.95 & 0.0000 \\
EM: & 0.0 & $1.76 \times 10^{-2}$ & 0.0 & 0.0 & 0.0 & 0.1 & 0.0 & 0.0 \\
PAT: & - & $\mathrm{COS}$ & - & - & - & $\mathrm{SIN}$ & - & - \\
\hline Lower layer & & & & & & & \\
\hline BL: & 24.5 & 0.07 & 0.224 & 0.171 & 0.0877 & 0.170 & 101.95 & 0.0266 \\
TOP: & 38.0 & 0.19 & 0.500 & 0.000 & 0.0000 & 0.000 & 101.95 & 0.0000 \\
EM: & 0.0 & $1.76 \times 10^{-2}$ & 0.0 & 0.0 & 0.0 & 0.1 & 0.0 & 0.0 \\
PAT: & - & $\mathrm{COS}$ & - & - & - & $\mathrm{SIN}$ & - & - \\
\hline Connected layers & & & & & & & \\
\hline BL: & 35.0 & 0.07 & 0.26 & 0.645 & 0.0765 & 0.176 & 101.95 & 0.0841 \\
TOP: & 47.0 & 0.10 & 0.42 & 0.000 & 0.0000 & 0.000 & 101.95 & 0.0000 \\
EM: & 0.0 & $1.76 \times 10^{-2}$ & 0.0 & 0.0 & 0.0 & 0.1 & 0.0 & 0.0 \\
PAT: & - & $\mathrm{COS}$ & - & - & - & $\mathrm{SIN}$ & - & - \\
\hline
\end{tabular}

be reproduced and explained. It is worthwhile to note that the longer the separation between shallow boundary layer and residual layer remains present, the stronger this morning peak is. Additionally, due to storage in the canopy under a stable boundary layer, $\mathrm{NO}_{\mathrm{x}}$ could accumulate near the surface during the night. When turbulence sets in, the canopy and ABL air masses interact, which could cause pulses in the surface exchange in the early morning (Ganzeveld et al., 2002).

The $\mathrm{O}_{3}$ mixing ratio in Fig. 8b does not show a sudden decrease or increase. However, it is apparent that the time evolution changes after the morning transition from a shallow to a merged boundary layer. The increase in $\mathrm{O}_{3}$ over time is not driven by surface exchange but mainly by entrainment. In this case chemistry has a smaller impact on the evolution of $\mathrm{O}_{3}$. In the shallow boundary layer the $\mathrm{O}_{3}$ mixing ratio is lower than in the residual layer. Therefore, entrainment causes the mixing ratio to rise in the growing shallow boundary layer. During the transition both layers are combined into one mixed layer. The rate of change of $\mathrm{O}_{3}$ in this merged boundary layer is altered due to two reasons: the mixing ratio in the atmospheric layer above the original residual layer is different and the entrained air is mixed over a larger mixing volume after the combination. In effect this results in a slower increase of the $\mathrm{O}_{3}$ mixing ratio. Note that the assumption of one well-mixed boundary layer from the start enables us to get a reasonable first approximation of the mixing ratio evolution. However, the representation in the morning is off and the differences in the rate of change of $\mathrm{O}_{3}$ before and after 09:30 LT can not be explained. By using the first order approximation to consider in succession the lower layer and connected layers cases, the time evolution of $\mathrm{O}_{3}$ can be explained and reproduced.

Our findings show that by using a relatively basic modelling tool, the mixed layer model, and using a first order approximation for the combining of a shallow boundary layer with a residual layer aloft, important features in the morning observations of chemical species can be reproduced and explained. We therefore conclude that the interpretation of atmospheric chemistry observations using a numerical model requires that dynamical processes are accounted for, including the boundary layer height evolution and the connection to a residual layer. This supports previous budget studies using the MXL model (Vilà-Guerau de Arellano et al., 2011; van Stratum et al., 2012) and a single column model (e.g., Ganzeveld et al., 2008).

\section{Reflection on the observational strategy during HUMPPA-COPEC-2010}

In this section, we extend the previous analysis to formulate recommendations for the observational strategy during 

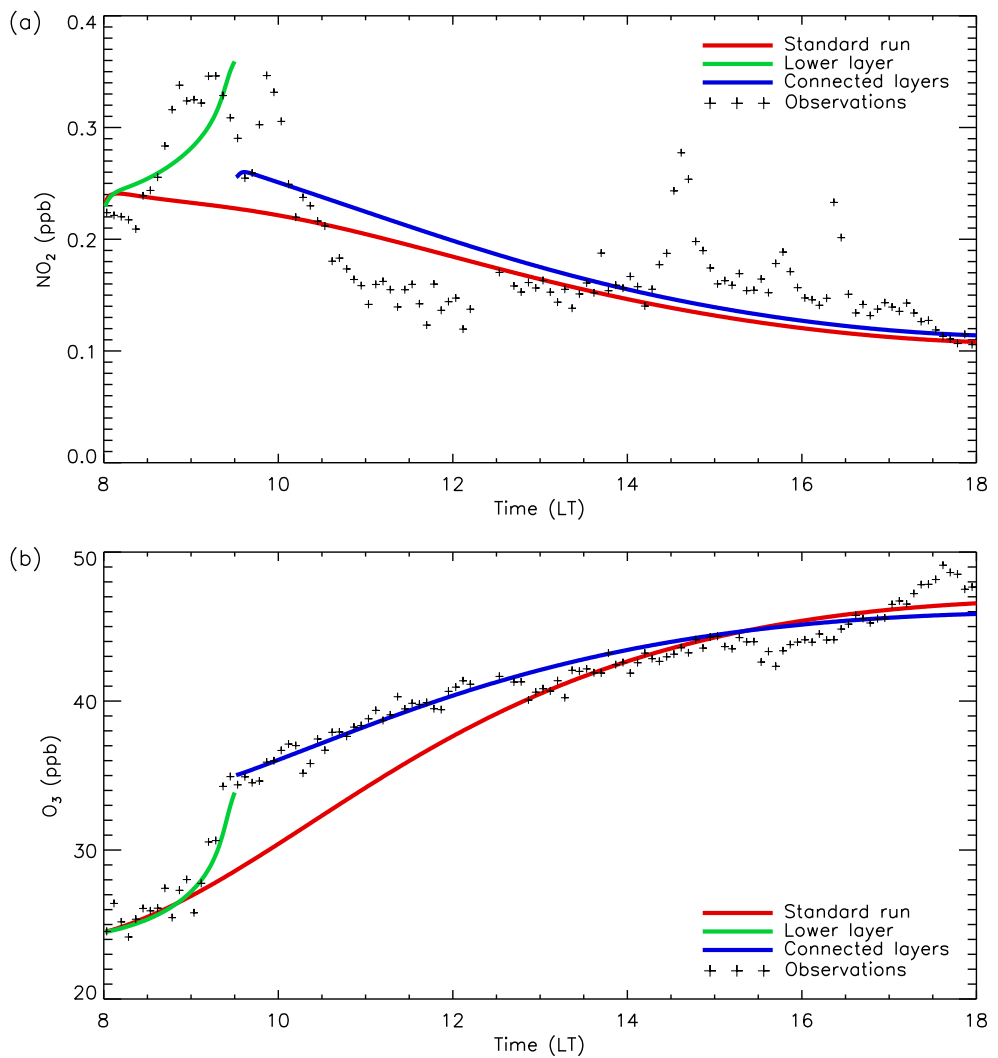

Fig. 8. Comparison between the observations and MXL model results for the (a) $\mathrm{NO}_{2}$ and (b) $\mathrm{O}_{3}$ mixing ratios during 6 August 2010. The numerical experiments are the standard case, the case for the lower shallow boundary layer until 09:30 LT and the case where a residual layer and the lower shallow boundary layer are connected and become one mixed layer from 09:30 LT onward. The latter two cases correspond to situation (1) and situation (3) in Fig. 2, respectively.

campaigns such as HUMPPA-COPEC-2010. The experience during the HUMPPA-COPEC-2010 campaign enables us to improve the strategy for future campaigns, resulting in an even more comprehensive set of atmospheric data.

As presented in Fig. 3, local observations can result in variations of the measured scalars under the influence of the boundary layer dynamics. For the potential temperature, the largest variations occur in the surface layer and near the inversion layer. The variability of the scalars is even enhanced by heterogeneous surface forcings (Ouwersloot et al., 2011). Thus, we conclude that for representative observations of the boundary layer dynamics it would be recommendable to launch multiple radiosondes simultaneously at key moments (e.g., morning transition, noon and evening transition) to account for the influences of heterogeneous terrain and local, instantaneous observations. In addition, these multiple radiosondes would provide important information about the spatial variations in the dynamical variables, which could be used to evaluate results of numerical models, including large scale chemistry-transport models.

Furthermore, the lowest few hundred meters of the atmosphere are important to characterize in detail. Within a convective boundary layer a surface layer is present in which the profiles of potential temperature, specific humidity and concentrations of chemical species can have significant vertical gradients. The nocturnal boundary layer, characterized by stable stratification, has a similar height as well. However, the observations during HUMPPA-COPEC-2010 did not suffice to fully characterize this part of the ABL. The observations at the towers are only performed at six fixed locations below $67 \mathrm{~m}$ and the radiosonde profiles near the surface are occasionally omitted due to limited transmission of the sonde data. To enable the characterization of the nocturnal boundary layer and the surface layer during the day, it is recommended to operate kytoons (tethered balloons) (Stull, 1988) with the relevant instruments for at least these lower areas. Due to the tether, no data will be lost and the speed of the ascend/descend during the profiling can be controlled.

As discussed in Sect. 3.2, another possible improvement to the employed observational strategy is to obtain information about large scale forcings, i.e. the subsidence velocity and horizontal advection of air masses. The information about subsidence could be estimated by comparing the boundary layer heights for subsequent observed profiles. This could be achieved by launching radiosondes within very short time intervals (maximum $1 \mathrm{~h}$ ). After calculating the entrainment 
velocity from the observed inversion layer properties and surface heat fluxes (Eq. A5), it can be subtracted from the observed $\mathrm{ABL}$ growth rate to determine the subsidence velocity (Eq. A4). In combination with the horizontal wind direction and velocity, the advection can be calculated from the horizontal gradients of the different scalars (Eq. A1). The influence of horizontal advection for potential temperature and specific humidity can therefore be determined by simultaneously launching at least 3 radiosondes around the observational site to obtain the horizontal distribution of these scalars. This approach has previously been applied to tower observations (e.g., Aubinet et al., 2003).

As presented in Fig. 4c, the observations during HUMPPA-COPEC-2010 enable a characterization of the development of ABL dynamics. However, for most days observations were limited to 5 radiosonde launches. During the intensive observation periods additional measurements were performed at relatively short time intervals, but even then continuous measurements are not available. A continuous representation of the ABL height would be relevant input for chemical box models as discussed in Sect. 3.3 and demonstrated in Fig. 7. Continuous observations could be obtained using a ceilometer, sodar (Nilsson et al., 2001), wind profiler (Bianco et al., 2011) or lidar (Gibert et al., 2007). This would also enable that the morning transition can be studied in greater detail, and more specifically the mixing of a shallow boundary layer with a residual layer aloft. Another advantage of continuous observations would be that fluctuations in the measurements due to local observations can be filtered by time averaging the data, according to Taylor's frozen turbulence hypothesis (Stull, 1988).

\section{Conclusions}

By combining observations, both near the surface and in the free troposphere, with a mixed layer model, we studied the atmospheric boundary layer dynamics as observed over the Finnish boreal forest during the HUMPPA-COPEC2010 campaign. Particular emphasis is placed on the role of atmospheric dynamics at different scales on the boreal atmospheric chemistry. We investigated the influence of large scale forcings (subsidence and advection) and the transition from nocturnal to daytime turbulent conditions on the development of the ABL.

The meteorological data has been classified by identifying boundary layer prototypes based on the vertical potential temperature profiles. During the campaign three different types were observed: the stable boundary layer, the convectively mixed boundary layer and the conditionally unstable layer above a mixed layer. Of these three types, the convective boundary layer was observed most often, 78 out of the 132 classified soundings. Illustrated by Large-Eddy Simulation model results, we discuss how instantaneous observed profiles can deviate from these prototypes.
By selecting a single day, characterized by a convective boundary layer, 6 August 2010, we studied in detail the key dynamic contributions that influence atmospheric chemistry. This analysis could be applied to other cases observed during HUMPPA-COPEC-2010. It is shown that by using a relatively basic numerical model, the mixed layer model (MXL), the evolution of the boundary layer dynamics can be reproduced and explained. A residual mixed layer in the early morning and the effects of two different large scale forcings, subsidence and horizontal advection, have been shown to be important. During this day, the horizontal advection of cold air results in a decrease of the temperature at the measurement site. Subsidence inhibits the boundary layer growth, causing a lower boundary layer height and consequently, due to a smaller mixing volume and unaltered sensible and latent heat fluxes, higher temperatures. By accounting for both subsidence and cold air advection, the modelled evolution for temperature is shown to remain approximately equal, though the resulting atmospheric boundary layer height evolution was significantly reduced.

It is demonstrated that the representation of atmospheric chemistry with a numerical model requires accurate knowledge of the ABL height evolution. Due to the dependency of the chemical reaction rates on the concentrations of chemical species, knowledge about the initial (early morning) chemical conditions, the surface emissions/deposition and the boundary layer height at one specific point in time does not suffice to accurately predict the concentrations of chemical species at that point in time.

The morning transition from a shallow boundary layer, merging with a residual mixed layer aloft into a combined mixed boundary layer, has been represented by combining two numerical experiments with the mixed layer model. The results show that by using this assumption, we are able to explain and represent an observed morning peak in the $\mathrm{NO}_{\mathrm{x}}$ concentrations and the increase of $\mathrm{O}_{3}$ concentrations with time.

By using the mixed layer model, several processes are identified that require attention during observational field campaigns if measured data is to be reproduced. We find that emphasis should be placed on continuous observations of the atmospheric boundary layer height, combined with model analyses. Using this combined information, the effects of mixing with the residual layer and the entrainment and dilution of chemical species can be evaluated. A continuous representation could be achieved by using radiosondes and (occasionally consecutive) simulations with a numerical model, although this method assumes a boundary layer that is characterized by the convective boundary layer prototype and requires knowledge of the large scale forcings. Therefore, we suggest the use of a ceilometer, sodar or lidar in future campaigns. 
a)

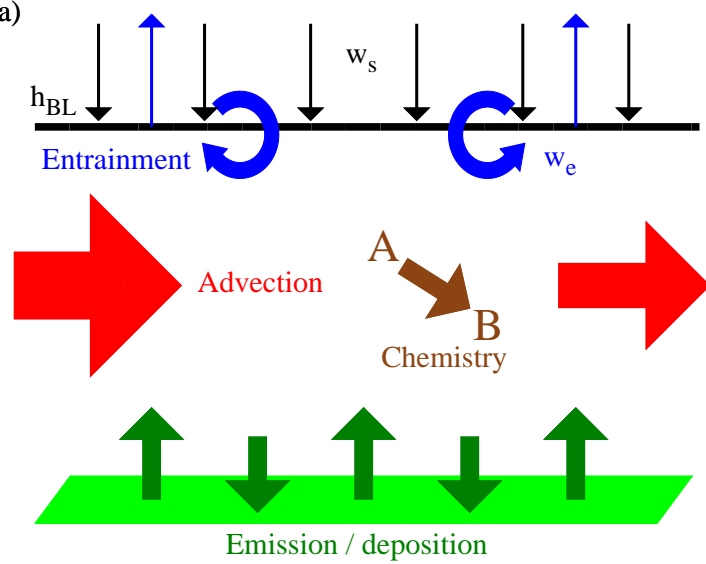

b)

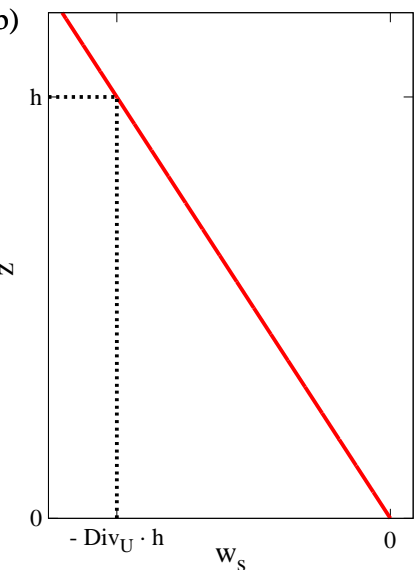

Fig. A1. (a) Schematic overview of the different terms that affect the evolution of scalars and the boundary layer height. Shown are the emissions and deposition near the surface, advection, entrainment, additional sources and sinks (e.g. due to chemical conversion) and subsidence. The dependence of the subsidence velocity on height is presented in (b).

\section{Appendix A}

\section{Mixed layer equations}

The prognostic equations are solved by the mixed layer model for multiple conserved scalar variables, $S$. These variables are the potential temperature, $\theta$, specific humidity, $q$, and the mixing ratios of chemical species, $c_{\text {species }}$. $\theta$ and $q$ influence the evolution of the ABL height. Since the ABL is well mixed during the day, the averages of the variables over the whole boundary layer, $\langle S\rangle$, can be used for the evaluation. The difference between the value at the bottom of the free troposphere and the value in the boundary layer is symbolized by $\Delta S$. The system of prognostic equations that solves $\langle S\rangle$ and $\Delta S$ is expressed by (Vilà-Guerau de Arellano et al., 2009):

$$
\begin{aligned}
\frac{\partial\langle S\rangle}{\partial t} & =\frac{\overline{w^{\prime} S^{\prime}}}{h}-\frac{\overline{w^{\prime} S^{\prime}}}{h}-\left(U \frac{\partial\langle S\rangle}{\partial x}+V \frac{\partial\langle S\rangle}{\partial y}\right)+R_{S}, \\
\frac{\partial \Delta S}{\partial t} & =\gamma_{S} w_{\mathrm{e}}-\frac{\partial\langle S\rangle}{\partial t} .
\end{aligned}
$$

An illustration of the different contributions to the boundary layer height development and to the prognostic equation for the boundary layer averaged scalars is presented in Fig. A1. The different terms are explained in more detail below.

$\overline{w^{\prime} S^{\prime}}$ s and $\overline{w^{\prime} S^{\prime}}$ are the surface and entrainment fluxes, respectively. The height of the mixed layer is $h . U$ and $V$ are the wind velocities in the $x$ and $y$ direction and the total term $-\left(U \frac{\partial\langle S\rangle}{\partial x}+V \frac{\partial\langle S\rangle}{\partial y}\right)$ is the advection of $S, \operatorname{Adv}_{S}$. The advection is positive if it leads to an increase in $S$. $R_{S}$ expresses additional sources or sinks for scalar $S$. In the case of a chemical species, $R_{S}$ is equal to the chemical production minus the chemical destruction of that species, based on the applied chemical mechanism. The vertical gradient in the free troposphere is expressed by $\gamma_{S}$. The velocity at which free tropospheric air is entrained into the boundary layer is symbolized by $w_{\mathrm{e}}$.

The surface fluxes are prescribed, though for the zerothorder jump assumption the entrainment flux at the top of the mixed layer is expressed by

$\overline{w^{\prime} S_{\mathrm{e}}^{\prime}}=-w_{\mathrm{e}} \Delta S$.

Next to the scalar variables, the boundary layer height evolution is included by applying

$\frac{\partial h}{\partial t}=w_{\mathrm{e}}+w_{\mathrm{s}}$.

Here, $w_{\mathrm{s}}$ is the large scale vertical velocity. If it is negative, $-w_{\mathrm{s}}$ is the subsidence velocity. It is related to the boundary layer height by $w_{\mathrm{s}}=-\operatorname{Div}_{U} h$, where $\operatorname{Div}_{U}$ is the velocity divergence in $\mathrm{s}^{-1}$. Note that this represents a linear profile with $w_{\mathrm{s}}=0$ at the surface, as presented in Fig. A1b. The entrainment velocity is diagnosed by solving

$w_{\mathrm{e}}=-\frac{\overline{w^{\prime} \theta_{\mathrm{ve}}^{\prime}}}{\Delta \theta_{\mathrm{v}}}$

together with the closure assumption that $\overline{w^{\prime} \theta_{\mathrm{ve}}^{\prime}}=-\beta \overline{w^{\prime} \theta_{\mathrm{vs}}^{\prime}}$, where usually $\beta=0.2$, even though more precise and complicated parametrisations exist (e.g., Pino et al., 2003). The virtual potential temperature, $\theta_{\mathrm{v}}$, that appears in this set of equations, is equal to

$\theta_{\mathrm{v}}=\theta(1+0.61 q)$,

which results in

$\overline{w^{\prime} \theta_{\mathrm{v}}^{\prime}} \approx(1+0.61 \bar{q}) \overline{w^{\prime} \theta^{\prime}}+0.61 \bar{\theta} \overline{w^{\prime} q^{\prime}}$,

$\Delta \theta_{\mathrm{v}}=\Delta \theta+0.61(\langle q\rangle \Delta \theta+\langle\theta\rangle \Delta q+\Delta \theta \Delta q)$.

Note that while using these equations, one should take units into account and therefore represent values for $q$ in $\mathrm{kg} \mathrm{kg}^{-1}$. 
Acknowledgements. H. O. gratefully acknowledges financial support by the Max Planck Society. The modelling part of this study was sponsored by the National Computing Facilities Foundation (NCF project SH-060-11) for the use of supercomputer facilities. I. M. acknowledges support from the Academy of Finland Center of Excellence program (project 1118615). The authors thank the colleagues who assisted in launching the radiosondes and Horst Fischer, Zeinab Hosaynali Beygi and Uwe Parchatka for providing the $\mathrm{NO}, \mathrm{NO}_{2}$ and $\mathrm{O}_{3}$ data.

The service charges for this open access publication have been covered by the Max Planck Society.

Edited by: M. Kanakidou

\section{References}

Aubinet, M., Heinesch, B., and Yernaux, M.: Horizontal and vertical $\mathrm{CO}_{2}$ advection in a sloping forest, Bound.-Lay. Meteorol., 108, 397-417, doi:10.1023/A:1024168428135, 2003.

Barr, A. G. and Betts, A. K.: Radiosonde boundary layer budgets above a boreal forest, J. Geophys. Res., 102, 29205-29212, doi:10.1029/97JD01105, 1997.

Betts, A. K.: Non-precipitating cumulus convection and its parameterization, Quart. J. R. Met. Soc., 99, 178-196, doi:10.1002/qj.49709941915, 1973.

Bianco, L., Djalalova, I. V., King, C. W., and Wilczak, J. M.: Diurnal Evolution and Annual Variability of Boundary-Layer Height and Its Correlation to Other Meteorological Variables in California's Central Valley, Bound.-Lay. Meteorol., 140, 491-511, doi:10.1007/s10546-011-9622-4, 2011.

Butler, T. M., Taraborrelli, D., Brühl, C., Fischer, H., Harder, H., Martinez, M., Williams, J., Lawrence, M. G., and Lelieveld, J.: Improved simulation of isoprene oxidation chemistry with the ECHAM5/MESSy chemistry-climate model: lessons from the GABRIEL airborne field campaign, Atmos. Chem. Phys., 8, 4529-4546, doi:10.5194/acp-8-4529-2008, 2008.

Carson, D. J.: The development of a dry inversion-capped convectively unstable boundary layer, Quart. J. R. Met. Soc., 99, 450467, doi:10.1002/qj.49709942105, 1973.

Cuijpers, J. W. M. and Duynkerke, P. G.: Large eddy simulation of trade wind cumulus clouds, J. Atmos. Sci., 50, 3894-3907, doi:10.1175/1520-0469(1993)050<3894:LESOTW $\rangle 2.0 . C O ; 2$, 1993.

Davis, K. J., Lenschow, D. H., and Zimmerman, P. R.: Biogenic non-methane hydrocarbon emissions estimated from tethered balloon observations, J. Geophys. Res., 99, 25587-25598, doi:10.1029/94JD02009, 1994.

Davis, K. J., Lenschow, D. H., Oncley, S. P., Kiemle, C., Ehret, G., Giez, A., and Mann, J.: Role of entrainment in surfaceatmosphere interactions over the boreal forest, J. Geophys. Res., 102, 29219-29230, doi:10.1029/97JD02236, 1997.

Deardorff, J. W.: Three-dimensional numerical modeling of the planetary boundary layer, in: Workshop on Meteorology, edited by: Haugen, D. A., Am. Meteorol. Soc., 271-311, Boston, USA, 1973.

Dosio, A., Vilà-Guerau de Arellano, J., Holtslag, A. A. M., and Builtjes, P. J. H.: Dispersion of a passive tracer in buoyancy- and shear-driven boundary layers, J. Appl. Meteor., 42, 1116-1130,
doi:10.1175/1520-0450(2003)042〈1116:DOAPTI $\rangle$ 2.0.CO;2, 2003.

Galmarini, S., Duynkerke, P. G., and Vilà-Guerau de Arellano, J.: Evolution of Nitrogen Oxide Chemistry in the Nocturnal Boundary Layer, J. Appl. Meteor., 36, 943-957, doi:10.1175/15200450(1997)036<0943:EONOCI > 2.0.CO;2, 1997.

Ganzeveld, L., Eerdekens, G., Feig, G., Fischer, H., Harder, H., Königstedt, R., Kubistin, D., Martinez, M., Meixner, F. X., Scheeren, H. A., Sinha, V., Taraborrelli, D., Williams, J., VilàGuerau de Arellano, J., and Lelieveld, J.: Surface and boundary layer exchanges of volatile organic compounds, nitrogen oxides and ozone during the GABRIEL campaign, Atmos. Chem. Phys., 8, 6223-6243, doi:10.5194/acp-8-6223-2008, 2008.

Ganzeveld, L. N., Lelieveld, J., Dentener, F. J., Krol, M. C., and Roelofs, G.-J.: Atmosphere-biosphere trace gas exchanges simulated with a single-column model, J. Geophys. Res., 107, 4297, doi:10.1029/2001JD000684, 2002.

Garratt, J. R.: The Atmospheric Boundary Layer, Cambridge University Press, Cambridge, UK, 151-154, 1992.

Gibert, F., Schmidt, M., Cuesta, J., Ciais, P., Ramonet, M., Xueref, I., Larmanou, E., and Flamant, P. H.: Retrieval of average $\mathrm{CO}_{2}$ fluxes by combining in situ $\mathrm{CO}_{2}$ measurements and backscatter lidar information, J. Geophys. Res., 112, D10301, doi:10.1029/2006JD008190, 2007.

Guenther, A., Karl, T., Harley, P., Wiedinmyer, C., Palmer, P. I., and Geron, C.: Estimates of global terrestrial isoprene emissions using MEGAN (Model of Emissions of Gases and Aerosols from Nature), Atmos. Chem. Phys., 6, 3181-3210, doi:10.5194/acp-63181-2006, 2006.

Hari, P. and Kulmala, M.: Station for measuring ecosystematmosphere relations (SMEAR II), Boreal Environ. Res., 10, 315-322, 2005.

Heus, T., van Heerwaarden, C. C., Jonker, H. J. J., Siebesma, A. P., Axelsen, S., van den Dries, K., Geoffroy, O., Moene, A., Pino, D., de Roode, S. R., and Vilà-Guerau de Arellano, J.: Formulation of the Dutch Atmospheric Large-Eddy Simulation (DALES) and overview of its applications, Geosci. Model Dev., 3, 415-444, doi:10.5194/gmd-3-415-2010, 2010.

Junninen, H., Lauri, A., Keronen, P., Aalto, P., Hiltunen, V., Hari, P., and Kulmala, M.: Smart-SMEAR: on-line data exploration and visualization tool for SMEAR stations, Boreal Environ. Res., 14, 447-457, 2009.

Kaimal, J. C., Wyngaard, J. C., Haugen, D. A., Coté, O. R., and Izumi, Y.: Turbulence structure in the convective boundary layer, J. Atmos. Sci., 33, 2152-2169, doi:10.1175/15200469(1976)033〈2152:TSITCB〉2.0.CO;2, 1976.

Kulmala, M., Hämeri, K., Aalto, P. P., Mäkelä, J. M., Pirjola, L., Douglas Nilsson, E., Buzorius, G., Rannik, U., Dal Maso, M., Seidl, W., Hoffmann, T., Janson, R., Hansson, H.-C., Viisanen, Y., Laaksonen, A., and O'Dowd, C. D.: Overview of the international project on biogenic aerosol formation in the boreal forest (BIOFOR), Tellus B, 53, 324-343, doi:10.1034/j.16000889.2001.530402.x, 2001.

Lelieveld, J., Butler, T. M., Crowley, J. N., Dillon, T. J., Fischer, H., Ganzeveld, L., Harder, H., Lawrence, M. G., Martinez, M., Taraborrelli, D., and Williams, J.: Atmospheric oxidation capacity sustained by a tropical forest, Nature, 452, 737-740, doi:10.1038/nature06870, 2008. 
Lilly, D. K.: Models of cloud-topped mixed-layer under a strong inversion, Q. J. Roy. Meteor. Soc., 94, 292-309, doi:10.1002/qj.49709440106, 1968.

Mammarella, I., Launiainen, S., Gronholm, T., Keronen, P., Pumpanen, J., Rannik, U., and Vesala, T.: Relative humidity effect on the high-frequency attenuation of water vapor flux measured by a closed-path eddy covariance system, J. Atmos. Ocean. Tech., 26, 1856-1866, doi:10.1175/2009JTECHA1179.1, 2009.

Nieuwstadt, F. T. M. and Brost, R. A.: The decay of convective turbulence, J. Atmos. Sci., 43, 532 - 545, doi:10.1175/15200469(1986)043<0532\%3ATDOCT $\rangle 2.0 . C O ; 2,1986$.

Nilsson, E. D., Rannik, U., Kulmala, M., Buzorius, G., and O'Dowd, C. D.: Effets of continental boundary layer evolution, convection, turbulence and entrainment, on aerosol formation, Tellus B, 53, 441-461, doi:10.1034/j.1600-0889.2001.530409.x, 2001.

Ouwersloot, H. G., Vilà-Guerau de Arellano, J., van Heerwaarden, C. C., Ganzeveld, L. N., Krol, M. C., and Lelieveld, J.: On the segregation of chemical species in a clear boundary layer over heterogeneous land surfaces, Atmos. Chem. Phys., 11, 1068110704, doi:10.5194/acp-11-10681-2011, 2011.

Pino, D., Vilà-Guerau de Arellano, J., and Duynkerke, P. G.: The Contribution of Shear to the Evolution of a Convective Boundary Layer, J. Atmos. Sci., 60, 1913-1926, doi:10.1175/15200469(2003)060<1913:TCOSTT>2.0.CO;2, 2003.

Sellers, P. J., Hall, F. G., Kelly, R. D., Black, A., Baldocchi, D., Berry, J., Ryan, M., Ranson, K. J., Crill, P. M., Lettenmaier, D. P., Margolis, H., Cihlar, J., Newcomer, J., Fitzjarrald, D., Jarvis, P. G., Gower, S. T., Halliwell, D., Williams, D., Goodison, B., Wickland, D. E., and Guertin, F. E.: BOREAS in 1997: Experiment overview, scientific results, and future directions, J. Geophys. Res., 102, 28731-28769, doi:10.1029/97JD03300, 1997.

Stull, R. B.: An Introduction to Boundary Layer Meteorology, Kluwer Academic Publishers, Dordrecht, The Netherlands, 519, p. 415, p. 547 and 562-568, 1988.

Sullivan, P. P., Moeng, C.-H., Stevens, B., Lenschow, D. H., and Mayor, S. D.: Structure of the entrainment zone capping the convective atmospheric boundary layer, J. Atmos. Sci., 55, 30423064, 1998.

Tennekes, H.: A model for the dynamics of the inversion above a convective boundary layer, J. Atmos. Sci., 30, 558-567, doi:10.1175/1520-0469(1973)030<0558:AMFTDO $>2.0 . C O ; 2$, 1973.

van Heerwaarden, C. C., Vilà-Guerau de Arellano, J., Gounou, A., Guichard, F., and Couvreux, F.: Understanding the daily cycle of evapotranspiration: a method to quantify the influence of forcings and feedbacks, J. Hydrometeor., 11, 1405-1422, doi:10.1175/2010JHM1272.1, 2010. van Stratum, B. J. H., Vilà-Guerau de Arellano, J., Ouwersloot, H. G., van den Dries, K., van Laar, T. W., Martinez, M., Lelieveld, J., Diesch, J.-M., Drewnick, F., Fischer, H., Hosaynali Beygi, Z., Harder, H., Regelin, E., Sinha, V., Adame, J. A., Sörgel, M., Sander, R., Bozem, H., Song, W., Williams, J., and Yassaa, N.: Case study of the diurnal variability of chemically active species with respect to boundary layer dynamics during DOMINO, Atmos. Chem. Phys., 12, 5329-5341, doi:10.5194/acp-12-5329-2012, 2012.

Vilà-Guerau de Arellano, J., van den Dries, K., and Pino, D.: On inferring isoprene emission surface flux from atmospheric boundary layer concentration measurements, Atmos. Chem. Phys., 9, 3629-3640, doi:10.5194/acp-9-3629-2009, 2009.

Vilà-Guerau de Arellano, J., Patton, E. G., Karl, T., van den Dries, K., Barth, M. C., and Orlando, J. J.: The role of boundary layer dynamics on the diurnal evolution of isoprene and the hydroxyl radical over tropical forests, J. Geophys. Res., 116, D07304, doi:10.1029/2010JD014857, 2011.

Vinuesa, J.-F. and Vilà-Guerau de Arellano, J.: Introducing effective reaction rates to account for the inefficient mixing of the convective boundary layer, Atmos. Environ., 39, 445-461, doi:10.1016/j.atmosenv.2004.10.003, 2005.

Williams, J., Crowley, J., Fischer, H., Harder, H., Martinez, M., Petäjä, T., Rinne, J., Bäck, J., Boy, M., Dal Maso, M., Hakala, J., Kajos, M., Keronen, P., Rantala, P., Aalto, J., Aaltonen, H., Paatero, J., Vesala, T., Hakola, H., Levula, J., Pohja, T., Herrmann, F., Auld, J., Mesarchaki, E., Song, W., Yassaa, N., Nölscher, A., Johnson, A. M., Custer, T., Sinha, V., Thieser, J., Pouvesle, N., Taraborrelli, D., Tang, M. J., Bozem, H., Hosaynali-Beygi, Z., Axinte, R., Oswald, R., Novelli, A., Kubistin, D., Hens, K., Javed, U., Trawny, K., Breitenberger, C., Hidalgo, P. J., Ebben, C. J., Geiger, F. M., Corrigan, A. L., Russell, L. M., Ouwersloot, H. G., Vilà-Guerau de Arellano, J., Ganzeveld, L., Vogel, A., Beck, M., Bayerle, A., Kampf, C. J., Bertelmann, M., Köllner, F., Hoffmann, T., Valverde, J., González, D., Riekkola, M.-L., Kulmala, M., and Lelieveld, J.: The summertime Boreal forest field measurement intensive (HUMPPA-COPEC-2010): an overview of meteorological and chemical influences, Atmos. Chem. Phys., 11, 1059910618, doi:10.5194/acp-11-10599-2011, 2011.

Yassaa, N., Song, W., Lelieveld, J., Vanhatalo, A., Bäck, J., and Williams, J.: Diel cycles of isoprenoids in the emissions of Norway spruce, four Scots pine chemotypes, and in Boreal forest ambient air during HUMPPA-COPEC-2010, Atmos. Chem. Phys., 12, 7215-7229, doi:10.5194/acp-12-7215-2012, 2012. 